\title{
OCCURRENCE REPORTING AND PROCESSING OF OPERATIONS INFORMATION
}

\section{U.S. DEPARTMENT OF ENERGY OFFICE OF ENVIRONMENT, SAFETY AND HEALTH}

DISTRIBUTION:

All Departmental Elements

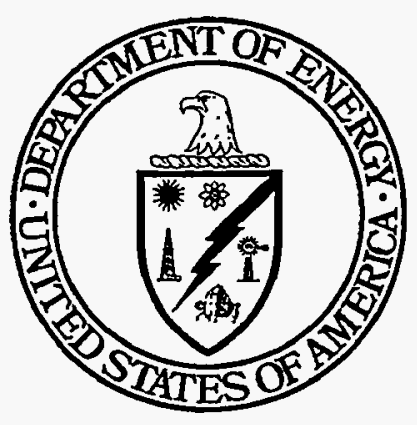

RECEIVED ANa 11 1198\%

OSTI 


\section{DISCLAIVIER}

Portions of this document may be illegible in electronic image products. Images are produced from the best available original document. 
DOE M 232.1-1A

i (and ii)

07-21-97

\section{SUBJECT: OCCURRENCE REPORTING AND PROCESSING OF OPERATIONS} INFORMATION

1. PURPOSE. This Manual provides detailed requirements to supplement DOE O 232.1A, OCCURRENCE REPORTING AND PROCESSING OF OPERATIONS

INFORMATION. This Manual is approved for use by all DOE Elements and their contractors.

2. REFERENCE. See DOE O 232.1A, OCCURRENCE REPORTING AND PROCESSING OF OPERATIONS INFORMATION.

3. CANCELLATION. DOE M 232.1-1, OCCURRENCE REPORTING AND PROCESSING OF OPERATIONS INFORMATION, of 9-25-95.

4. CONTACT. Beneficial comments and any pertinent data that may improve this document should be sent to: Eugenia Boyle, Office of Nuclear and Facility Safety (EH-3), at Internet address EUGENIA.BOYLE@EH.DOE.GOV or 301-903-3393.

BY ORDER OF THE SECRETARY OF ENERGY:

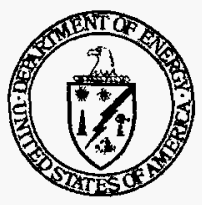

ARCHER L. DURHAM

Assistant Secretary for

Human Resources and Administration 


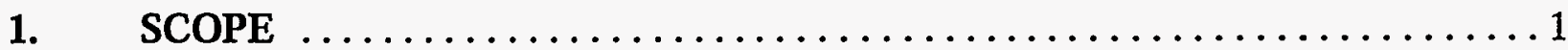

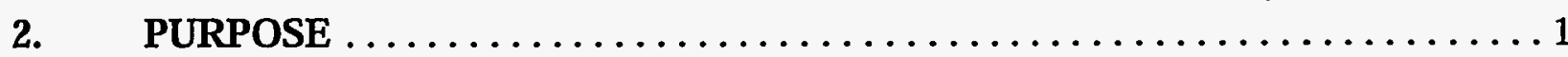

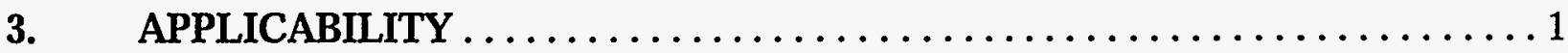

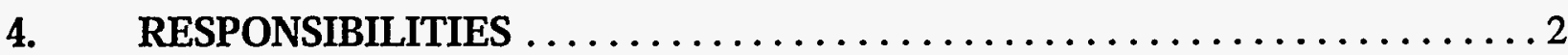

4.1 Assistant Secretary for Environment, Safety and Health $(\mathrm{EH}-1) \ldots \ldots \ldots 2$

4.2 Secretarial Officers . . . . . . . . . . . . . . . . . . . . . . . . 2

4.3 Director, Office of Emergency Management $(\mathrm{NN}-60) \ldots \ldots \ldots \ldots \ldots \ldots$

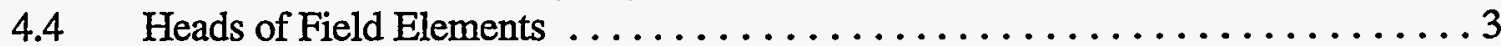

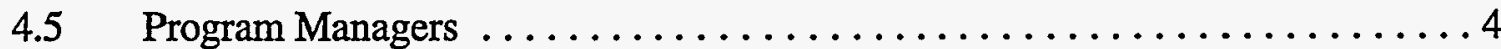

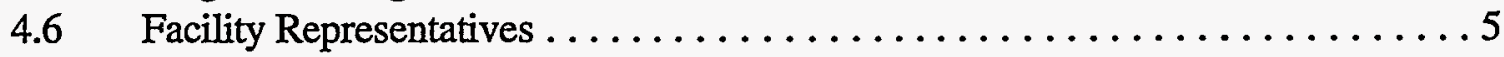

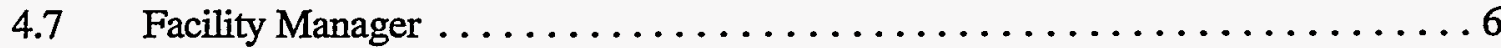

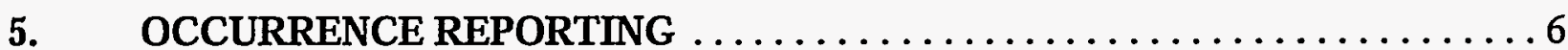

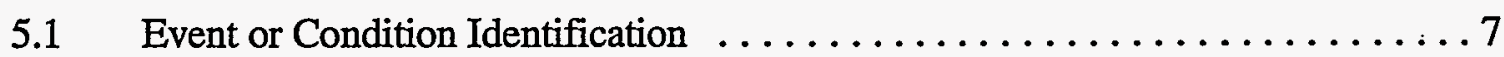

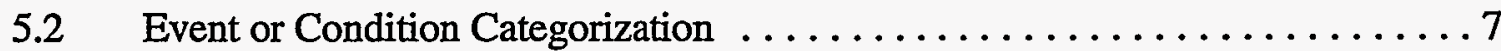

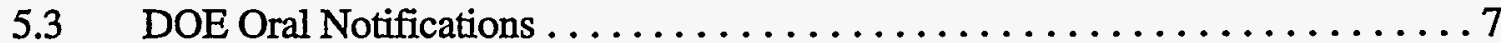

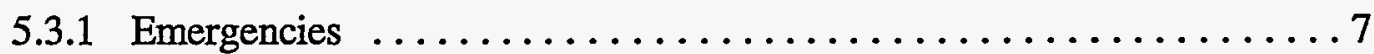

5.3 .2 Unusual Occurrences $\ldots \ldots \ldots \ldots \ldots \ldots \ldots \ldots \ldots \ldots$

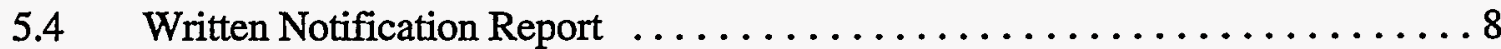

5.5 Occurrence Investigation and Analysis $\ldots \ldots \ldots \ldots \ldots \ldots \ldots \ldots \ldots$

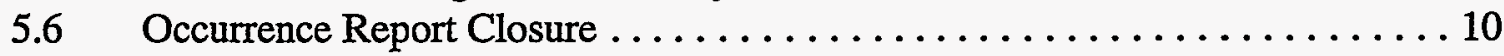

5.7 Roll-Up Occurrence Reports for Off-Normal Occurrences . . . . . . . . . . 11

5.7.1 Similar Occurrences Documented in Non-Finalized Occurrence Report

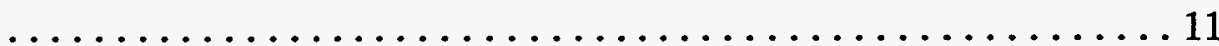

5.7.2 Similar Occurrences Based on Corrective Actions in an Approved Final

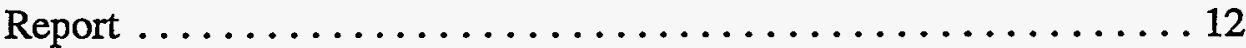

5.7.3 Roll-Up Report Instructions . . . . . . . . . . . . . . . . 14 5.7.3.1 Roll-Up Report Format for Similar Occurrences Documented in a Non-Finalized Occurrence Report . . . 14 5.7.3.2 Roll-Up Report Format for Similar Occurrences Previously Documented in an Approved Final Report ....... 15

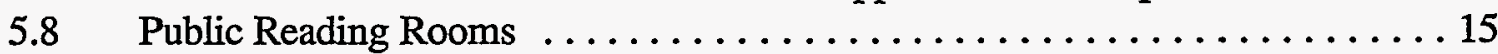

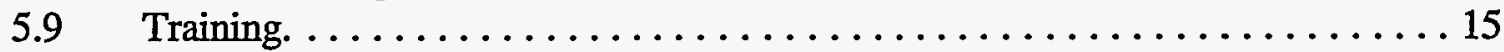

6. INFORMATION SECURITY REQUIREMENTS . . . . . . . . . . 15 
7. UTILIZATION OF REPORTABLE OCCURRENCE INFORMATION . . . . 16

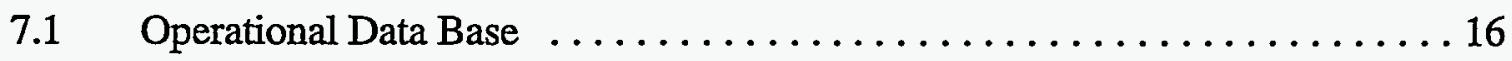

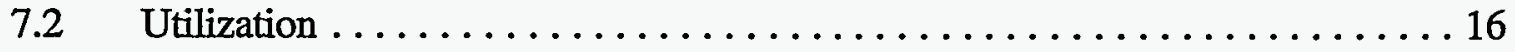

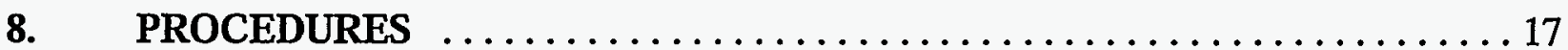

9. CATEGORIZATION OF REPORTABLE OCCURRENCES $\ldots \ldots \ldots \ldots \ldots \ldots$

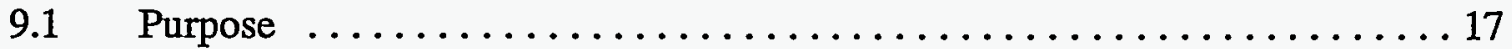

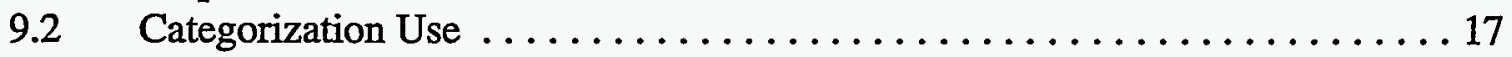

9.3 Categorization of Occurrences by Group $\ldots \ldots \ldots \ldots \ldots \ldots \ldots \ldots \ldots \ldots \ldots \ldots$

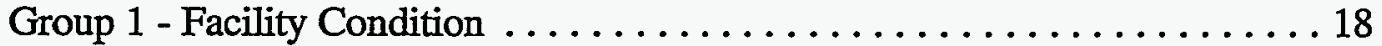

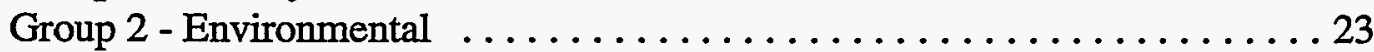

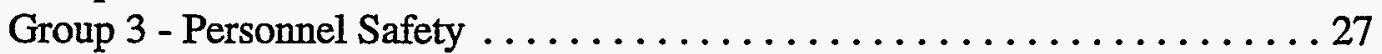

Group 4 - Personnel Radiological Protection .................. 29

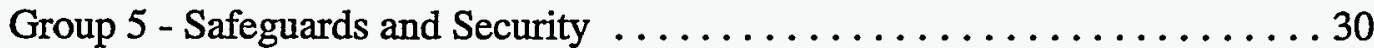

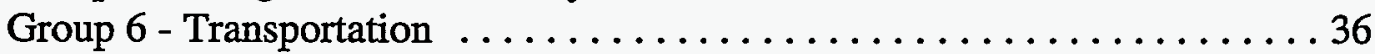

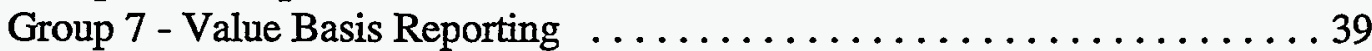

Group 8 - Facility Status .............................. 40

Group 9 - Nuclear Explosive Safety $\ldots \ldots \ldots \ldots \ldots \ldots \ldots \ldots \ldots \ldots \ldots \ldots \ldots$

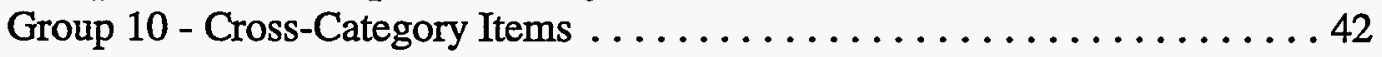

10. INSTRUCTIONS FOR COMPLETING AN OCCURRENCE REPORT . . . . . 43

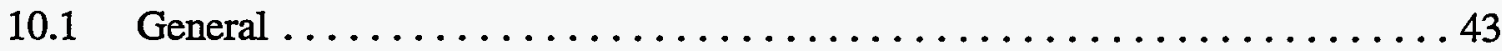

10.2 Occurrence Report Items $\ldots \ldots \ldots \ldots \ldots \ldots \ldots \ldots \ldots \ldots \ldots \ldots 4$

10.3 Reporting Radiological Contamination Occurrences $\ldots \ldots \ldots \ldots \ldots \ldots 60$

10.3.1 Personnel Contamination Occurrences ..................61 61

10.3.2 Area or Facility Contamination Occurrences $\ldots \ldots \ldots \ldots \ldots \ldots 62$

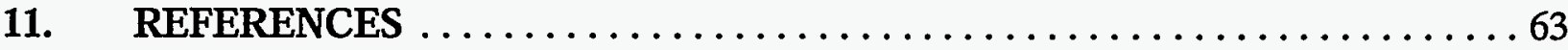

APPENDIX A

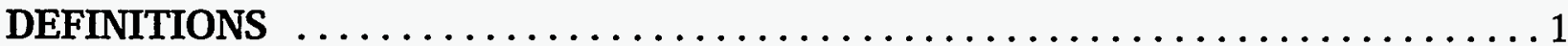

\section{APPENDIX B}

SURFACE ACTIVITY GUIDELINES

Allowable Total Residual Surface Activity (dpm/100 sq-cm) $\ldots \ldots \ldots \ldots \ldots 1$ 
07-21-97

1. SCOPE. DOE O 232.1A, OCCURRENCE REPORTING AND PROCESSING OF OPERATIONS INFORMATION, and 10 CFR 830.350, "Occurrence Reporting and Processing of Operations Information" (when it becomes effective), along with this Manual, set forth occurrence reporting requirements for Department of Energy (DOE) Departmental Elements and contractors responsible for the management and operation of DOE-owned and leased facilities. These requirements include categorization of occurrences related to safety, security, environment, health, or operations ("Reportable Occurrences"); DOE notification of these occurrences; and the development and submission of documented follow-up reports. These occurrence reporting directives further require that the notifications be timely in accordance with the significance of the occurrence, and that the written reports contain appropriate information describing the occurrence, significance, causal factors, and corrective actions.

2. PURPOSE. This Manual provides detailed information for categorizing and reporting occurrences at DOE facilities. It complements DOE O 232.1A and its use is required by that Order. It also complements 10 CFR 830.350, "Occurrence Reporting and Processing of Operations Information" (when it becomes effective). Information gathered by the Occurrence Reporting and Processing System is used for analysis of the Department's performance in environmental protection, safeguards and security, and safety and health of its workers and the public. This information is also used to develop lessons learned and document events that significantly impact DOE operations.

\section{APPLICABILITY.}

a. DOE Elements. Except for the exclusions in paragraph 3.c, this Manual applies to all DOE Elements.

b. Contractors. Except for the exclusions in paragraph 3.c, the Contractor Requirements Document (CRD) for DOE O 232.1A sets forth requirements that are to be applied to the universe of DOE contractors and subcontractors thereunder who are awarded contracts for the management and operation of DOE-owned and -leased facilities.

c. Exclusions.

(1) Operations information for activities regulated by the Nuclear Regulatory Commission or a State under an agreement with the Nuclear Regulatory Commission.

(2) Power Marketing Administrations' reporting of major electrical power outages, disturbances, and fuel shortages subject to the emergency power system reporting requirements prescribed in 10 CFR 205, 350 through 354, "Report of Major Electric Utility Systems Emergencies." 
(3) The Naval Nuclear Propulsion Program, as described in Executive Order 12344 and Public Law 98-525, "The Department of Defense Authorization Act, 1985."

4. RESPONSIBILITIES. The following provides primary responsibilities for implementation of the Occurrence Reporting Program. Other specific responsibilities are provided elsewhere in the Manual.

\subsection{Assistant Secretary for Environment, Safety and Health (EH-1).}

a. Develop, promulgate, and maintain policies to implement and sustain an effective Occurrence Reporting Program.

b. Provide formal Departmental interpretation of the requirements of this Manual.

c. Develop, promulgate, and maintain guidance materials, and conduct workshops, as necessary, for implementing the requirements of this Manual.

d. Monitor reports relative to reporting activities at DOE facilities to assess implementation of this Manual to identify needed improvements.

e. Monitor and audit implementation of this Manual related to the Office of Environment, Safety and Health functional areas of responsibility.

f. Review facility/site implementing procedures for the Occurrence Reporting Program and provide any issues to the appropriate Secretarial Office.

\subsection{Secretarial Officers.}

a. Delegate responsibilities and authority for implementing this Manual, to include designation of Program Managers.

b. Review and approve the Facility/Site Implementation Procedure after coordination with the Office of Environment, Safety and Health. Provide a copy of the implementing procedure to EH-33 upon approval.

c. Establish agreements with Heads of Field Elements to ensure support to the Facility Representative and Program Manager(s) in accordance with this Manual.

d. Review Occurrence Reports and identify circumstances that are indicative of deteriorating or poor program performance in their respective areas of authority. 
e. If deemed appropriate, delegate authority for initiating Roll-Up Reports and approval of Final "Off-Normal" Occurrence Reports from the cognizant Program Manager to the cognizant Facility Representative.

f. If deemed necessary, formally request the Secretary of Energy to grant an exemption to the reporting requirements of this Manual, after obtaining concurrence from the Office of Environment, Safety and Health. The Secretarial Officer may grant temporary exemptions to the reporting requirements of this Manual, up to 1 year in duration. The Office of Environment, Safety and Health should be notified prior to approval of the temporary exemption.

g. Ensure training programs are established for both DOE and contractor personnel.

h. Ensure the requirements in the CRD for DOE O 232.1A are applied to applicable contracts within 3 months after approval of this Order.

i. Ensure initiators of procurement requests identify in procurement requests whether the requirements in the CRD for DOE O 232.1A are to be applied to the award or subawards resulting from the procurement request and any special instructions for the application of the CRD.

\subsection{Director, Office of Emergency Management (NN-60).}

Ensure that the Emergency Operations Center is prepared to receive and record incoming initial notifications of Unusual Occurrences and disseminate these reports to appropriate Headquarters organizations.

\subsection{Heads of Field Elements.}

a. Ensure that agreements are established with responsible Secretarial Officers on the working relationship between the Secretarial Officer and the Field Element for the purpose of carrying out the requirements of this Manual.

b. Assess capability and performance of the facility personnel in carrying out the requirements of this Manual, in accordance with established agreements with the responsible Secretarial Officers.

c. Provide technical support as necessary to Facility Representatives in responding to any reportable occurrence, in accordance with established agreements with the responsible Secretarial Officers. 
d. Designate and direct Facility Representatives and Designees to fulfill the responsibilities required by this Manual.

e. Ensure the requirements in the CRD for DOE $\mathrm{O} 232.1 \mathrm{~A}$ are applied to applicable contracts within 3 months after approval of this Order.

f. Ensure initiators of procurement requests identify in procurement requests whether the requirements in the CRD for DOE O 232.1A are to be applied to the award or subawards resulting from the procurement request and any special instructions for the application of the CRD.

4.5 Program Managers (in addition to other requirements prescribed by this Manual).

a. Review activities relating to reportable occurrences, including reporting and development of programs and procedures.

b. Ensure that a system for prompt notification and categorization of reportable occurrences has been established for their DOE programs and for facilities under their cognizance.

c. Ensure that the Headquarters Emergency Operations Center is informed of how the Program Manager or Designees can be reached at all times.

d. Ensure that lessons learned and generic or programmatic implications are identified and elevated to the Secretarial Officer for appropriate action.

e. Ensure that actions are taken to minimize or prevent recurrence.

f. Review and assess reportable occurrence information from facilities under their cognizance to assess the Facility Manager s and Facility Representative s evaluation of significance, root cause, generic implications, and corrective action(s) implementation and closeout, and to ensure that DOE and contractor staff involved in these operations perform the related functions.

g. Ensure that Occurrence Reports and operations information from other organizations are disseminated to appropriate DOE and contractor activities within their cognizance, are reviewed for generic implications, and are used to improve operations.

h. Ensure that Occurrence Reports are prepared and transmitted in accordance with DOE information security requirements (see Section 6).

i. Notify the cognizant Secretarial Officer of all Unusual Occurrences. 
j. Interact with the Facility Representative and HQ oversight organizations as necessary, and inform and advise their respective management of their findings.

k. Elevate any unresolved issues regarding actions or determinations on a reportable occurrence to the Secretarial Officer and, if necessary, the Secretary for resolution and direction.

4.6 Facility Representatives (in addition to other requirements prescribed in this Manual).

a. Ensure that facility personnel under their cognizance prepare and promulgate procedures for notification and reporting that are compatible with and serve the policies of this Manual.

b. Actively monitor day-to-day operations and performance of facilities/activities under their cognizance.

c. Ensure that lessons learned and generic or programmatic implications are identified and elevated to the Head of the Field Element for appropriate action.

d. Ensure that facility personnel act to minimize or prevent recurrence.

e. Review and assess reportable occurrence information from facilities under their cognizance to assess acceptability and significance of root causes, generic implications, and corrective action(s) implementation and closeout, and to ensure that facility personnel involved in these operations perform the related functions.

f. Ensure that Occurrence Reports and operations information from other organizations are disseminated to appropriate facility personnel within their cognizance, are reviewed for generic implications, and are used to improve operations.

g. Ensure that Occurrence Reports are prepared and transmitted in accordance with DOE information security requirements (see Section 6).

h. Notify the appropriate Head of the Field Element of reportable occurrences.

i. Interact with facility personnel and Field Element oversight organizations as necessary and inform and advise their respective management of their findings.

j. Elevate any unresolved issues regarding actions or determinations on a reportable occurrence to the Program Manager for resolution and direction.

k. Be available at all times to satisfy the requirements of this Manual. 
4.7 Facility Manager (in addition to other requirements prescribed in this Manual).

a. Ensure procedures are implemented for notification and reporting that are compatible with and serve the policies of this Manual.

b. Actively monitor day-to-day operations and performance of facilities/activities under their cognizance.

c. Identify lessons learned and generic or programmatic implications from occurrences and take actions to minimize or prevent recurrence.

d. Determine root causes, generic implications, and implement corrective action(s) and closeout activities for reportable occurrences.

e. Disseminate Occurrence Reports and operations information from other organizations, review for generic implications, and use to improve operations.

f. Prepare and transmit Occurrence Reports in accordance with DOE information security requirements.

g. Be available at all times to satisfy the requirements of this Manual.

5. OCCURRENCE REPORTING. To implement the occurrence categorization, notification, reporting, and processing system, the key responsible personnel shall be identified and procedures developed, approved, and implemented to ensure that the system objectives are met. In addition, plant-specific procedures for the categorization of occurrences that reflect the variation in facility type, purpose, and design shall be developed. The Facility Manager shall be available at all times to carry out the responsibilities for the categorization, notification, and reporting requirements. Facility operators are required to ensure that occurrences resulting from activities performed by subcontractors in support of facility operation are reported in accordance with the provisions of this Manual.

For reportable occurrences, facility personnel are required to categorize the occurrences, notify DOE, and prepare and submit Occurrence Reports. This section addresses the process for meeting these requirements, including roles and actions for key facility personnel and the steps to be taken to ensure performance.

The documentation and distribution requirements can be satisfied by utilization of a centralized unclassified DOE operational data base, presently the computerized Occurrence Reporting and Processing System (ORPS). However, under no circumstances shall Occurrence Reports containing classified information or Unclassified Controlled Nuclear Information (UCNI) be entered into the ORPS data base. Requirements regarding security classification are provided in Section 6. 
07-21-97

\subsection{Event or Condition Identification.}

a. Operations personnel shall take appropriate immediate action to stabilize and/or place the facility/operation in a safe condition, any potential environmental effects are stabilized, and workers are treated for injuries sustained. Also, actions should be taken to preserve conditions for continued investigation; however, these actions are not to interfere with establishing a safe condition.

b. The facility staff and operators shall, upon identification of an abnormal or suspected abnormal event or condition, promptly notify the appropriate line management and the Facility Manager of the event status and record and/or archive all pertinent information, including details concerning the discovery of the occurrence and actions taken to stabilize or place the facility/operation in a safe condition.

5.2 Event or Condition Categorization. The Facility Manager shall categorize the occurrence within two hours of identification by the cognizant facility staff following the facility-specific procedures developed in accordance with Section 8 of this Manual. If the category is not clear or the occurrence exceeds the threshold of more than one criteria, the occurrence shall be categorized at the higher level being considered. As an example, discovery of a defective item, material, or service, normally reportable as an Off Normal Occurrence, that caused the reduction of safety margin below that prescribed in the authorization basis, would be reported as an Unusual Occurrence. The occurrence category shall either be elevated, maintained, or lowered as information is made available.

\subsection{DOE Oral Notifications.}

5.3.1 Emergencies. The requirements for the initial and follow-up notifications to DOE and other agencies and the appropriate emergency responses to be taken are provided in DOE O 151.1, COMPREHENSIVE EMERGENCY MANAGEMENT SYSTEM. The specific procedures on how these events are categorized and how and when DOE is notified are included in the facility or site specific emergency response plans or procedures. If an event has been declared an Emergency, the Facility Manager will be responsible for the written Notification Report and for the completion of all other occurrence reporting requirements, as described below.

5.3.2 Unusual Occurrences. The Facility Manager shall notify DOE of an Unusual Occurrence as soon as practical, but no later than 2 hours after categorization. The Facility Manager shall contact the Facility Representative and the DOE Headquarters Emergency Operations Center (EOC), which will notify the Program Manager of all Unusual Occurrences and make any further notifications required. 
a. The Facility Manager shall orally notify the HQ EOC who will have the phone call recorded. The HQ EOC can then play the tape back to the HQ staff and the Program Manager.

b. Initial notification to DOE Headquarters EOC may be made by voice or electronic transmittal. Electronic transmittal, such as a facsimile, is preferred. All notifications shall include a valid contact point including name and telephone number. Electronically transmitted reports must be confirmed by phone to ensure receipt and document the time of official notification. Voice notifications may be recorded by the EOC and played back for further notification.

c. Initial notification shall include as many of the required report fields, identified with an asterisk (*), as possible as discussed in Section 10 below. The Facility Manager may use the local Field/Site Emergency Operations Center to expedite establishing the communication link required and to record and archive conversations.

d. All information should be clear and succinct. Avoid jargon. Uncommon or facility/site-specific abbreviations and acronyms should be fully described.

e. The Facility Manager shall follow the appropriate security procedures if the notification to DOE may contain classified or sensitive information.

f. If an Off-Normal Occurrence is upgraded to an Unusual Occurrence, the Facility Manager shall notify the HQ EOC as soon as practical, but no later than 2 hours after recategorization, that an existing occurrence has been upgraded, and provide the HQ EOC with the Occurrence Report number. The HQ EOC will make any required internal DOE HQ notifications.

g. Follow-up notifications shall be made to DOE for any further degradation in the level of safety or impact on the environment, safeguards and security, health, or operations of the facility or other worsening conditions subsequent to the previous notification, including upgrading to an Emergency in accordance with DOE O 151.1, COMPREHENSIVE EMERGENCY MANAGEMENT SYSTEM.

5.4 Written Notification Report. The Facility Manager shall prepare the Notification Report (including all required fields and all other fields for which information is known) and distribute it to the Facility Representative and the Program Manager before the close of the next business day from the time of categorization (not to exceed 80 hours). When an unclassified, nonsensitive Notification Report is entered onto the computerized ORPS data base, the distribution requirement is automatically satisfied. 
Any changes in categorization shall be documented in an Update Report and submitted before the close of the next business day from the time of recategorization (not to exceed 80 hours). A justification for the new categorization shall be included in the report.

5.5 Occurrence Investigation and Analysis. The following steps describe an acceptable process for submitting Update Reports and conducting the investigation and analysis. DOE 5480.19, CONDUCT OF OPERATIONS REQUIREMENTS FOR DOE FACILITIES, and DOE-STD-1045-93, Guide to Good Practices for Notifications and Investigation of Abnormal Events, should be considered when establishing a program for investigation of occurrences. The investigative process is used to gain an understanding of the occurrence, its causes, and the corrective actions necessary to prevent recurrence.

a. The Facility Manager should consider a graded approach when determining the level of effort for the investigation into the cause of the occurrence. The graded approach is based on the severity or risk associated with the event or condition. For example, investigations of a significant Unusual Occurrence might require the assembly of a team of investigators and subject matter experts, whereas the investigation into an Off-Normal might be completed during the critique/factfinding meeting process. Many occurrences should be investigated using one or more of the formal analytical models discussed in DOE-NE-STD-1004-92, Root Cause Analysis Guidance Document .

b. The Facility Manager shall submit and distribute an Update Report if there is any significant and new information about the occurrence. The status of the investigation, recurring consequences, or the identification of additional component defects are activities associated with the occurrence and shall be included in Update Reports.

When additional occurrences are to be included in a Roll-Up Report, an update shall be submitted, in accordance with Section 5.7, by the close of the next business day from the time of categorization (not to exceed 80 hours).

c. The Facility Manager should consult in a timely manner with the Facility Representative and the Program Manager for their assessment, if any, of the occurrence. If the ORPS data base is being used, the Facility Representative's and Program Manager's comments should be obtained via the data base. 
5.6 Occurrence Report Closure. The following steps describe an acceptable process for closing out the Final Report.

a. The Final Report shall be prepared by the Facility Manager and submitted to the Facility Representative as soon as practical but within 45 calendar days after initial categorization of the occurrence. The Final Report shall document the following:

(1) the significance, nature, and extent of the event or condition;

(2) the cause(s) of the event or condition, including the root cause;

(3) the corrective action(s) to be taken (with actual or target completion dates identified) to correct the condition and prevent recurrence; and

(4) any identified lessons learned.

b. If the required analysis cannot be completed within 45 calendar days after initial categorization, an Update Report shall be submitted within the 45 days. The Update Report shall provide a detailed explanation of the delay and provide an estimated date for submittal of the Final Report. This information shall be reported in the "Evaluation" block of the Occurrence Report. It is expected that most occurrences will be completed and the Final Report submitted within the 45 calendar days. However, for certain occurrences, such as those requiring an accident investigation, it is understood that the information required for the Final Report may not be available within this time.

c. The Facility Representative shall review, approve, add any comments, and forward the Final Report to the Program Manager within 10 calendar days after receipt of the report. The Program Manager shall review, approve, and add any comments to the Final Report within 14 calendar days after receipt. If the ORPS data base is being used, the Facility Representative's and Program Manager's comments should be provided through ORPS. Facility Representative and Program Manager comments are not required for their approval of the report.

d. If the Final Report is not approved by either the Facility Representative or the Program Manager, it shall be returned to the Facility Manager with a written explanation for the disapproval. The revised Final Report shall be resubmitted within 21 calendar days of the disapproval. If it cannot be resubmitted within this time, an Update Report shall be submitted within the 21 calendar days explaining the delay and providing an estimated date for resubmittal of the Final Report. This information shall be reported in the "Evaluation" block of the Occurrence Report. 
e. The Occurrence Reports (update and final) shall be distributed as soon as practical to the following:

- Facility Representative

- Program Manager

- Affected program self-assessment group

- Heads of all Field organizations

- Office of Environment, Safety and Health (EH-1)

- DOE Management and Operations or Integrating contractors

- Office of Operating Experience Analysis and Feedback (EH-33)

If the Occurrence Reports are entered into the ORPS data base, the distribution requirement is automatically satisfied. A copy of the unapproved Final Report will be automatically entered as an Update Report when the Final Report is transmitted to the host computer.

f. The cognizant Facility Manager shall keep the status of Final Report corrective actions current on the ORPS data base. A status report of all incomplete Occurrence Reports (not final) and incomplete corrective actions shall be available at any time from the ORPS data base.

g. Retain all supporting information pertaining to each occurrence or report (e.g., graphs, analyses, and formal investigation reports) in accordance with Departmental Records Disposition Schedules, as required by 36 CFR Chapter 12, Subchapter B, RECORDS MANAGEMENT.

5.7 Roll-Up Occurrence Reports for Off-Normal Occurrences. Two basic types of RollUp Reports are permitted for Off-Normal Occurrences only.

5.7.1 Similar Occurrences Documented in Non-Finalized Occurrence Report. Roll-Up Reports are permitted when a Final Report has not been approved for similar occurrences that meet the threshold requirements of this Manual and are expected to have the same root cause code (Field \#22), the same or similar direct and contributing causes, and the same or similar corrective actions. The following conditions must be met:

a. An Occurrence Report has been initiated, to include notification or Update Reports, but not finalized.

b. The preliminary investigation identifies the subsequent occurrence to be similar and have the same root cause code. 
c. The preliminary investigation identifies the subsequent occurrence to have the same or similar direct and contributing causes as the initial occurrence.

d. The preliminary corrective actions for the initial occurrence are expected to correct the same root cause type of failure.

e. Appropriate corrective actions have been added to address direct and/or contributing causes identified for each new occurrence added to the report.

f. The Facility Representative and Program Manager agree to include these occurrences in a Roll-Up Report. For Group 6 - Transportation occurrences, agreement must also be obtained from the Office of Transportation, Emergency Management and Analytical Services (EM-76).

g. The Facility Representative agrees to the addition of each subsequent occurrence to the Roll-Up Report.

h. The notification of the added occurrence is made through the issuance of an Update Report within the normal time period required for issuance of a Notification Report, changing Field \#4, Number of Occurrences, appropriately.

For example, if there are multiple area radiation monitors used within a facility and monitor failure was attributed to inadequate or defective design, a Notification Report is prepared and submitted as normally required. If, prior to finalizing the initial occurrence, additional monitors fail through similar mechanisms, only an update to the Occurrence Report is required, as long as the above conditions were met.

\subsubsection{Similar Occurrences Based on Corrective Actions in an Approved Final} Report. Roll-Up Reports are permitted for occurrences that meet the threshold requirements of this Manual for which a Final Report, including the root cause and corrective actions, has been approved by DOE. The candidates for Roll-Up Reports must have the same causal factors and corrective actions identified in the final approved report. This type of RollUp Report is permitted only when all the following conditions are met.

a. A Final Report has been approved by the Facility Representative and Program Manager including the corrective action(s) and associated schedules for implementation.

b. Similar occurrences with the same root cause and corrective actions occur in the time between the approval of the original Occurrence Report and completion of the corrective actions identified therein. 
c. The Facility Representative and Program Manager agree to include these occurrences in a Roll-Up Report. For Group 6 - Transportation occurrences, agreement must also be obtained from the Office of Transportation, Emergency Management and Analytical Services (EM-76).

d. Notification of the new occurrence is completed through the issuance of a Notification Report that references the previous report.

e. The Facility Representative agrees to the addition of each subsequent occurrence to the Roll-Up Report.

f. The notification of the added occurrence is made through the issuance of an Update Report within the normal time period required for issuance of a Notification Report, changing Field \#4, Number of Occurrences , appropriately.

g. Once the original approved Final Report corrective actions are completed (e.g., new system is installed and operating), a Final Report must be submitted for any open Roll-Up Reports referencing this original Occurrence Report as justification for a Roll-Up Report. This original approved Final Report cannot be used as the basis for future Roll-Up Reports, i.e., subsequent occurrences must be reported individually in compliance with this Manual.

As an example, a facility experiences a failure of a Continuous Air Monitor, which is a Safety Class component, and prepares Notification and Final Reports. The root cause was an inadequate design unable to maintain the sample paper in the location necessary for obtaining a representative air sample. The corrective action is the redesign and installation of a new bracket on the filter housing. Since DOE line management has been made aware of the problem through the initial report and has agreed to the corrective action, subsequent identical failures on identical pieces of equipment with this same root cause (i.e., same design flaw), which are reported in the interval between approval of the initial Final Report and completion of the corrective action, may be included in a Roll-Up Report (if agreed to by the responsible Facility Representative and Program Manager ). 


\subsubsection{Roll-Up Report Instructions.}

A Roll-Up Report may remain open for a period not to exceed 90 calendar days from categorization of the first occurrence reported therein or when the number of occurrences reported equals 30 . Once either of those limits is reached, a Final Report must be submitted.

If after initial roll-up of an occurrence, the causes and corrective actions of that occurrence are found to be different than originally thought, then that specific occurrence will be deleted from the Roll-Up Report through the submittal of an Update Report followed by the submittal of a new Occurrence Report.

Field \#4, "Number of Occurrences," should be continually updated as new occurrences are identified and should reflect the total number of occurrences reported. The first occurrence in a Roll-Up Report will be identified as "1."

Field \#16, "Description of the Occurrence," and Field \#19, "Immediate Actions Taken and Results," should clearly identify each new occurrence with a heading such as "Occurrence No. 1, 2, 3,..." and include a discussion of each additional occurrence. Field \#16 should also include the appropriate information described in Fields \#7, 10, $11,13,17$, and 18 for each subsequent occurrence.

\subsubsection{Roll-Up Report Format for Similar Occurrences Documented in a Non- Finalized Occurrence Report.}

(1) Field \#14, "Subject/Title of the Occurrence," should contain the word "Roll-Up" enclosed in parentheses at the end of the title.

(4) Field \#26 should contain corrective actions required to correct all of the identified causes, i.e., direct, contributing and root, of all of the occurrences. 


\subsubsection{2}

(1)
Roll-Up Report Format for Similar Occurrences Previously Documented in an Approved Final Report.

Field \#4 should also indicate the Occurrence Report number of the original approved Final Report.

Field \#14, "Subject/Title of the Occurrence," should be the same as the original approved Final Report with the word "RollUp" enclosed in parentheses at the end of the title.

Fields \#20 - 22 should contain the same root, direct, and contributing causes as the approved Final Report.

Field \#26 should contain the corrective actions and schedule identified in the approved Final Report.

5.8 Public Reading Rooms. All unclassified, nonsensitive Final Reports, with the exception of final canceled reports, shall be placed in the local reading room within 2 weeks of final approval. When occurrence reports are placed in local public reading rooms, a copy shall be forwarded to the DOE Headquarters reading room.

5.9 Training. Training programs for the requirements of this Manual shall be established for both DOE and contractor personnel for facilities under their cognizance. These training programs shall include:

a. Indoctrination in the objectives and process of occurrence reporting as defined in the occurrence reporting requirements documents.

b. Identification of reportable occurrences; their categorization, notification, and associated reporting requirements; analysis, determination of causal factors and generic implications; and implementation, tracking and close-out of corrective actions.

c. Utilization of ORPS including input of occurrence reports and obtaining information from the data base.

6. INFORMATION SECURITY REQUIREMENTS. Occurrence Reports containing any classified information or UCNI shall not be entered into the ORPS data base. However, with the exception of entry into the ORPS data base, the reporting requirements identified in this manual shall be met. In addition, an unclassified, nonsensitive version of the Occurrence Report shall be submitted to ORPS within the required time frames. Implementing procedures should include or reference requirements for distribution of reports containing classified or sensitive information. 
Note: For some period of time, UCNI data may still be present in the ORPS data base; therefore, appropriate security procedures related to sensitive data need to be followed.

\section{UTILIZATION OF REPORTABLE OCCURRENCE INFORMATION.}

7.1 Operational Data Base. The Office of Environment, Safety and Health (EH-1) is responsible for maintaining an unclassified central data base, the Occurrence Reporting and Processing System (ORPS). Occurrence Report documentation and distribution requirements shall be satisfied by utilization of ORPS, with the exception of those involving classified information or UCNI. Reports for occurrences involving classified information or UCNI will be prepared in written form. After the classified information and UCNI is removed, the report shall be entered into ORPS.

7.2 Utilization. Facility staff at each facility or group of facilities should collect and disseminate to their personnel information from occurrences related to their facilities and similar DOE facilities, including lessons to be learned from this information. Each Facility Manager should use this information for trending and analysis and for early identification and correction of deteriorating conditions. The Facility Manager, Facility Representative, and Program Manager should regularly utilize the information from the ORPS data base to identify good practices and lessons learned from other facilities that can be used in their own facilities.

One of the major purposes of this reporting system is to provide feedback of safety and operational information identified in the Occurrence Reports to other DOE facilities. In addition, Headquarters oversight and self-assessment organizations should use ORPS information to prepare Safety Notices and other feedback documents. These uses are dependent on the quality of the information reported, which means the information should be thorough and accurate. To this end, Occurrence Reports should contain sufficient information about the facility operations and the occurrence to facilitate action by other personnel who are unfamiliar with details of the facility, equipment, process, or procedures.

Operations and engineering units, as well as other support organizations, should be involved in the identification and assessment of reportable occurrences. Site information, such as operations logs and engineering evaluations, should be used in this process.

Engineering judgment should be used during the review of events and conditions to ensure that precursors to occurrences are identified and reported. An occurrence that is not serious, given the conditions under which it happened, may under different initial conditions be a precursor to a serious event at the same or other facilities. 
8. PROCEDURES. Departmental Elements and contractors at facilities shall develop and maintain implementing procedures for occurrence reporting requirements applicable to their facilities. Implementation procedures shall be submitted for approval to the responsible DOE Secretarial Office within 4 months of incorporating the requirements in the CRD into a new or existing contract. Implementation procedures submitted by the contractor or facility operator shall be considered automatically approved 2 months after submittal, if they are not deliberately approved or rejected by DOE prior to the automatic approval. A copy of the implementing procedure shall be provided to EH-33 upon approval. Implementation procedures shall include the following:

a. Responsibilities of the facility line management and staff.

b. Categorization, notification, reporting, and investigation requirements for each facility.

c. A listing (by reference) of the Safety Class Structures, Systems, and Components (SSC) for nuclear facilities and Safety Significant SSC for both nuclear and nonnuclear facilities.

d. Any other facility-specific reporting requirements based on Section 9 of this Manual.

\section{CATEGORIZATION OF REPORTABLE OCCURRENCES.}

9.1 Purpose. This section categorizes occurrences so that DOE and facility personnel can understand the degree of significance associated with Unusual and Off-Normal Occurrences. It provides a minimum set of requirements necessary to develop local procedures and report occurrences applicable to their operations.

Occurrences are arranged into 10 groups related to DOE operations. These groupings are used solely for ease of reference and consistency in data base structures. Site specific items are expected to be added when required.

9.2 Categorization Use. The 10 groups of categorized occurrences are as follows.

1. Facility Condition

2. Environmental

3. Personnel Safety

4. Personnel Radiological Protection

5. Safeguards and Security

6. Transportation

7. Value Basis Reporting

8. Facility Status

9. Nuclear Explosive Safety

10. Cross-Category Items 
The categories of occurrences are designed to be generic. For example, the environmental section (Group 2) provides much less detail than would be found in a site-specific matrix of occurrences, which typically lists hazardous materials and limits specific to a particular operation. The objective of this approach is to allow individual sites to fit their site-specific requirements to these categories. Note that some occurrences may fit in more than one group.

The Occurrence Reporting Requirements Documents and this Manual do not absolve the cognizant parties from making required reports to other agencies.

DOE O 151.1, COMPREHENSIVE EMERGENCY MANAGEMENT SYSTEM, establishes facility implementation procedures for Emergencies, including the reporting criteria and oral notification requirements. This Manual shall be used to satisfy the written reporting requirements for Emergencies.

\subsection{Categorization of Occurrences by Group}

\section{Group 1 - Facility Condition}

\section{A. Nuclear Criticality Safety .}

\section{Unusual Occurrence}

Violation of the double contingency criticality specifications such that no valid controls are available to prevent a criticality accident.

\section{Off-Normal}

Any nuclear criticality safety violation or infraction of procedures not covered by other reporting criteria. For example, violation of a single contingency such that only one valid criticality control remains in place.

\section{B. Fires/Explosions}

\section{Unusual Occurrence}

Any fire or explosion within primary confinement/containment boundaries of a nuclear facility.

\section{Off-Normal}

(1) Any fire or explosion not required to be reported as an Unusual Occurrence that activates a fire suppression system (e.g., halon discharge, sprinkler heads activating) or disrupts normal facility operations. 
(2) An unplanned fire that takes longer than 10 minutes to extinguish following the arrival of fire protection personnel; this does not include fires that do not disrupt normal facility operations and which are in the initial or beginning stage that can be controlled or extinguished by portable fire extinguishers, Class II standpipe, or small hose systems without the need for protective clothing or breathing apparatus.

\section{Safety Status Degradation}

\section{Unusual Occurrence}

(1) Any violation or noncompliance of an approved Technical Safety Requirement (Technical Specification or Operational Safety Requirement) or other operational safety limit defined by the contractor/DOE.

(2) Discovery of an incorrectly derived Technical Safety Requirement (Technical Specification or Operational Safety Requirement) or other operational safety limit defined by the contractor/DOE.

(3) Any operation outside the authorization basis of the facility or process.

(4) Any occurrence that would prevent immediate facility or offsite emergency response capabilities.

(5) Discovery of an actual Unreviewed Safety Question (USQ) which reveals a currently existing inadequacy in the approved authorization basis.

\section{Off-Normal}

(1) Discovery of a condition that leads the facility operating personnel to limit facility operations, either self-imposed or due to the identification of a potential degradation of the authorization bases of a facility or process. This includes the discovery of analytical errors, omissions, or inadequacies that present the potential for a USQ.

(2) Discovery of a potential USQ that could affect the present or future operation of the facility. Routine USQ determinations due to planned system or operational modifications are not reportable under this criteria.

D. Loss of Control of Radioactive Material/Spread of Radioactive Contamination

\section{Unusual Occurrence}

(1) Identification of radioactive contamination offsite in excess of 100 times any of the surface contamination levels specified in DOE 5400.5, RADIATION PROTECTION OF THE PUBLIC AND THE ENVIRONMENT, Figure IV-1, that has not been 
previously identified and formally documented. For the first group listed in Figure IV1 (i.e., transuranics...) use the values specified in Table 1 (provided as Appendix B to this Manual) of the EH-412 memorandum "Application of DOE 5400.5 Requirements for Release and Control of Property Containing Residual Radioactive Material", dated November 17, 1995.

(2) Loss of accountability of a sealed source or identification of lost radioactive material that exceeds 100 times the quantities specified in DOE N 441.1, RADIOLOGICAL PROTECTION FOR DOE ACTIVITIES.

(3) Any fissile material in a process or nonprocess system outside primary confinement boundaries not designed or expected to accommodate such material.

\section{Off-Normal}

(1) Any unplanned spill of liquids in excess of one gallon contaminated with radioactive material in concentrations greater than five times the Derived Concentration Guide values listed in DOE 5400.5, Figure III-1.

(2) Identification of radioactive contamination outside a radiological area (as defined in 10 CFR 835, Occupational Radiation Protection) or radiological buffer area established for contamination control, but within a Controlled Area, in excess of 10 times the total contamination levels in $10 \mathrm{CFR} 835$, Appendix D. For tritium, until a total contamination value is specified by 10 CFR 835 Appendix $D$, report contaminations in excess of 10 times $10,000 \mathrm{dpm} / 100 \mathrm{~cm}^{2}$.

(3) Identification of radioactive contamination onsite that is not located within a Controlled Area, Fixed Contamination Area, or Soil Contamination Area, and is in excess of two times the total contamination levels in 10 CFR 835, Occupational Radiation Protection, Appendix D. For tritium, until a total contamination value is specified by 10 CFR 835 Appendix D, report contaminations in excess of 2 times $10,000 \mathrm{dpm} / 100 \mathrm{~cm}^{2}$.

(4) Identification of radioactive contamination offsite in excess of any of the surface contamination levels specified in DOE 5400.5, Figure IV-1, that has not been previously identified and formally documented. For the first group listed in Figure IV1 (i.e., transuranics...) use the values specified in Table 1 (provided as Appendix B to this Manual) of the EH-412 memorandum "Application of DOE 5400.5 Requirements for Release and Control of Property Containing Residual Radioactive Material", dated November 17, 1995.

(5) Loss of accountability of a sealed source or identification of lost radioactive material that exceeds ten times and is less than 100 times the quantities specified in DOE $N$ 441.1, RADIOLOGICAL PROTECTION FOR DOE ACTIVITIES. 
07-21-97

(6) Loss of accountability of a sealed source or identification of lost radioactive material that is one to ten times the quantities specified in DOE $N$ 441.1, RADIOLOGICAL PROTECTION FOR DOE ACTIVITIES.

E. Safety Structure/System/Component Degradation

\section{Unusual Occurrence}

Performance degradation of any Safety Class Structure, System, or Component (SSC) that prevents satisfactory performance of its design function when it is required to be operable or in operation.

\section{Off-Normal}

(1) Performance degradation of any Safety Class SSC that prevents satisfactory performance of its design function when it is not required to be operable or in operation.

(2) Performance degradation of any nuclear or nonnuclear Safety Significant SSC that prevents satisfactory performance of its design function when it is required to be operable or in operation.

F. Violation/Inadequate Procedures

\section{Unusual Occurrence}

(1) Maintenance performed on Safety Class SSC without meeting the required plant conditions for nonavailability resulting in a performance degradation.

(2) Incorrect maintenance (including calibration) on or unauthorized modifications to Safety Class SSC that was required to be operable or in operation and results in a performance degradation.

Off-Normal

(1) Any violation resulting in actual equipment damage in excess of $\$ 10,000$.

(2) Use of inadequate procedures or deviations from written procedures that result in adverse effects on performance, safety, or reliability.

(3) Incorrect maintenance (including calibration) on or unauthorized modifications to Safety Significant SSC required to be operable or in operation. 
G. Oversight Activities

Unusual Occurrence

Any internal/external oversight activity discovering unsatisfactory operation, testing, maintenance, or modification of any Safety Class SSC that is required to be operable or in operation.

\section{Off-Normal}

Any internal/external oversight activity discovering unsatisfactory operation, testing, maintenance, or modification of any Safety Significant SSC required to be operable or in operation.

H. Operations This section should be augmented to include specific events that interfere with the safe, efficient, and productive operation of the facility, system, or process as approved by DOE. Each facility should conduct a comprehensive assessment to identify the facility's unique potential events.

\section{Unusual Occurrence}

(1) Actuation of Safety Class SSC or their alarms resulting from an actual unsafe condition. Inadvertent alarms are not required to be reported unless an actuation of a Safety Class SSC occurs and the actuation is considered significant as defined by the approved facility procedures. Actuation of continuous air monitoring systems identified as Safety Class equipment do not have to be reported if their actuation was found to be due to radon-thoron effects on the system or their actuation is expected due to maintenance tasks and other planned operations in the facility where the potential for release of radioactivity is anticipated to occur and the workers are appropriately protected.

(2) Loss of incoming alternating current power and failure of any backup emergency power system to operate, when the backup emergency power system supplies power to a Safety Class SSC.

(3) Weather conditions/natural phenomenon causing serious disruption of facility activities.

(4) Loss of process ventilation system serving a confinement function, which results in the loss of confinement. 
(5) Any facility evacuation (excluding office space) in response to an actual occurrence, not including a precautionary evacuation for an event that can be controlled and mitigated by employees or maintenance personnel assigned to the affected facility or activity.

\section{Off-Normal}

(1) Any unplanned and unexpected change in a process condition or variable adversely affecting safety, security, environment, or health protection performance sufficient to require termination of a procedure in a reactor or nonreactor facility.

(2) Any unplanned electrical outages or unexpected consequences from a planned outage which seriously disrupt normal operations of a facility and/or may prevent the facility from meeting approved operating goals.

(3) Any unplanned outages of service systems (i.e., cooling water, steam, phones, communication systems, etc.) or unexpected consequences from a planned outage which:

- disrupt normal operations for one week or longer and

- which adversely affect safety, security, environment or health protection performance.

(4) Loss of any process ventilation system serving a confinement function which does not result in the loss of confinement.

(5) Actuation of Safety Significant SSC or their alarms resulting from an actual unsafe condition. Inadvertent alarms are not required to be reported. Actuation of continuous air monitoring systems identified as Safety Significant equipment does not have to be reported if their actuation was found to be due to radon-thoron effects on the system or their actuation is expected due to maintenance tasks and other planned operations in the facility where the potential for release of radioactivity is anticipated to occur and the workers are appropriately protected.

\section{Group 2 - Environmental}

A. Radionuclide Releases

\section{Unusual Occurrence}

(1) Release of a radioactive material that violates environmental requirements in Federal permits, Federal regulations, or requirements established under DOE directives. 
(2) Any release that is not an Emergency as defined in DOE O 151.1 but which requires immediate reporting (less than 4 hours) to Federal regulatory authorities. Release of a radioactive material that exceeds a federally permitted release by the amount of a Comprehensive Environmental Response, Compensation and Liability Act reportable quantity or, where no federally permitted release exists, the release exceeds the reportable quantity or triggers specific action levels for an outside Federal agency.

\section{Off-Normal}

(1) Any release of radioactive material to controlled or uncontrolled areas that is not part of normal monitored release and which exceeds $50 \%$ of a Comprehensive Environmental Response, Compensation and Liability Act reportable quantity specified for such material per 40 CFR 302.

(2) Any controlled release of radioactive material that occurs as a monitored part of normal operations that exceeds what historical data and/or analysis show is expected as a result of normal operations.

(3) Any monitored facility or site boundary where exposure or concentration exceed what historical data and/or analysis show is expected as a result of normal operations.

(4) Any detection of a radionuclide in a sanitary or storm sewer, waste or process stream, or any holding points where such a material is not expected.

(5) Any controlled, uncontrolled, or accidental release not classified as an Unusual Occurrence but will be reported in writing to State/local agencies in a format other than routine periodic reports.

B. Release of Hazardous Substances/Regulated Pollutants/Oil

\section{Unusual Occurrence}

(1) Release of a hazardous substance or regulated pollutant that exceeds a Comprehensive Environmental Response, Compensation and Liability Act reportable quantity per 40 CFR 302 and 40 CFR 355 for chemicals and extremely hazardous substances.

(2) Any release that is not an Emergency as defined by DOE O 151.1, COMPREHENSIVE EMERGENCY MANAGEMENT SYSTEM but which requires immediate (less than 4 hours) reporting to Federal regulatory agencies or triggers specification action levels for an outside Federal agency. 
(3) Any discharge of 100 gallons or more of oil of any kind or in any form, including, but not limited to, petroleum, fuel oil, sludge, oil refuse, and oil mixed with wastes other than dredged spoil. For operations involving oil field crude or condensate, any discharge of 100 barrels or more is reportable under this criteria.

\section{Off-Normal}

(1) Release of a hazardous substance or regulated pollutant to controlled or uncontrolled areas that is not part of a normal, monitored release and which exceeds $50 \%$ of a Comprehensive Environmental Response, Compensation and Liability Act reportable quantity as specified for such material per 40 CFR 302.

(2) Any discharge of greater than 42 gallons of oil of any kind or in any form, including, but not limited to, petroleum, fuel oil, sludge, oil refuse, and oil mixed with wastes other than dredged spoil outside of a permitted containment area. For operations involving oil field crude oil or condensate, any discharge less than the Unusual Occurrence level but in excess of 10 barrels.

(3) Any detection of a toxic or hazardous substance in a sanitary or storm sewer, waste or process stream, or any holding points where such a material is not expected to be found considering the current detection method and historical detection method used.

(4) Any controlled, uncontrolled, or accidental release not classified as an Unusual Occurrence but which will be reported in writing to State/local agencies in a format other than routine periodic reports.

(5) Any controlled release of hazardous/regulated material that occurs as a monitored part of normal operation but exceeds what historical data and/or analysis shows is expected as a result of normal operations.

(6) Any general environmental monitoring where concentration increases to a level which exceeds what historical data and/or analysis shows is expected as a result of normal operations.

\section{Hazardous Material Contamination}

\section{Unusual Occurrence}

(1) Discovery of onsite or offsite contamination due to DOE operations that does not represent an immediate threat to the public but exceeds a reportable quantity for such material per 40 CFR 302. 
(2) Any discovery of groundwater contamination due to DOE operations that is not part of an existing plume previously identified in either an annual report or in any Comprehensive Environmental Response, Compensation and Liability Act/Resource Conservation and Recovery Act activity or report.

\section{Off-Normal}

Discovery of onsite contamination due to DOE operations that exceeds $50 \%$ of a reportable quantity for such material per 40 CFR 302.

D. Ecological Resources

\section{Unusual Occurrence}

Any occurrence causing significant impact to any ecological resource for which the DOE is a trustee (i.e., destruction of a critical habitat, damage to a historic/archeological site, damage to wetlands, etc.).

E. Environmental Agreement/Compliance Activities

\section{Unusual Occurrence}

Any occurrence under any agreement or compliance area that requires notification of an outside regulatory agency within 4 hours or less, or triggers any outside regulatory agency action level.

\section{Off-Normal}

(1) Any agreement, compliance, remediation or permit-mandated activity for which formal notification of enforcement has been received from the relevant outside regulatory agency that a site/facility is considered to be in noncompliance with a schedule or requirement (e.g., Notice of Violation, Notice of Deficiency, Notice of Intent to Sue, Notice of Noncompliance, Warning Letter, Finding of Violation, Finding of Alleged Violation, or a similar type enforcement action).

(2) Any occurrence under any agreement or compliance area that will be reported to outside agencies in a format other than routine periodic reports. 
07-21-97

\section{Group 3 - Personnel Safety}

A. Occupational Illness/Injuries

Unusual Occurrence

(1) Any occurrence due to DOE operations resulting in a fatality or terminal injury or illness.

(2) Any one occurrence resulting in 3 or more lost workday cases as defined by 29 CFR 1904.12 and Office of Management and Budget (OMB) No. 1200-0029.

(3) Any occurrence requiring in-patient hospitalization of 3 or more personnel or that has a high probability of resulting in a permanent disability.

(4) Personnel exposures to sufficient levels of hazardous substances or hazards that require the administration of medical treatment on the same day as the exposure and are above limits established by the Occupational Safety and Health Administration (refer to 29 CFR 1910) or American Conference of Governmental Industrial Hygienists (ACGIH), whichever is lower. These should include:
(a) Noise
(b) Non-ionizing radiation
(c) Chemical Agents
(d) Physical Agents
(e) Biological Agents

(5) Exposures to an immediately dangerous to life and health (IDLH) (as defined by 29 CFR 1910.120) condition without both appropriate personal protective equipment and procedures in place.

\section{Off-Normal}

(1) Any occupational illness or injury that results in inpatient hospitalization.

(2) Series of occupational illnesses from one event involving 3 or more people where at least one is a lost work day case. 
(3) Personnel exposure in a single event to hazardous substances or hazards in excess of limits, as established by the Occupational Safety and Health Administration (refer to 29 CFR 1910), or American Conference of Governmental Industrial Hygienists (ACGIH), whichever is lower. These should include:
(a) Noise
(b) Non-ionizing radiation
(c) Chemical Agents
(d) Physical Agents
(e) Biological Agents

B. Vehicular Incidents This section covers vehicular transportation incidents, including DOE or DOE contractor operated aircraft. Group 6 should also be considered in categorization for reporting. Transportation incidents without injury (e.g., those involving hazardous or radioactive material or financial loss) must be reported per the requirements of Group 6 or 7 .

\section{Unusual Occurrence}

(1) Any vehicular incident resulting in fatality(s), injury(s), or illness classified under Group 3.A, Unusual Occurrence.

(2) Any vehicular incident involving Departmental property with a fatality(s) to a person(s) other than DOE personnel or DOE contractor personnel.

\section{Off-Normal}

(1) Any vehicular incident with injury(s) involving Departmental property resulting in a lost workday case.

(2) Any vehicular incident involving Departmental property with injury(s) to a person(s) other than DOE personnel or DOE contractor personnel.

C. Safety Concerns Special attention should be paid to augmenting this section during the development of site-specific procedures.

\section{Off-Normal}

(1) Unapproved use of flammable, toxic, explosive, corrosive, or other unsafe or dangerous processes, chemicals, materials, or methods not in accordance with standard operating procedures or work plans.

(2) Any shutdown of a work activity taken as a result of an Occupational Safety and Health Administration violation (e.g., trenching without adequate shoring or working at elevated levels without fall protection, when required). 
07-21-97

\section{Group 4 - Personnel Radiological Protection}

A. Radiation Exposure Unless specified otherwise, all doses specified in the following requirements are calculated as the total effective dose equivalent, which is the sum of the committed effective dose equivalent due to radionuclides taken into the body (internal exposure) and the effective dose equivalent due to external exposure.

\section{Unusual Occurrence}

Determination of a dose that exceeds the limits specified in 10 CFR 835, Subpart C, Occupational Radiation Protection (for onsite exposure) or DOE 5400.5, Chapter II, Section 1 (for offsite exposures to a member of the public).

\section{Off-Normal}

(1) Any single occupational exposure that exceeds an expected exposure by $100 \mathrm{mrem}$.

(2) A single unplanned exposure onsite to a minor or member of the public that exceeds 50 mrem.

(3) Determination of a dose that exceeds the reporting requirement thresholds specified in DOE 5400.5, Chapter II, Section 7, for offsite exposures to a member of the public.

\section{B. Personnel Contamination}

\section{Unusual Occurrence}

(1) Any single occurrence resulting in the contamination of five or more personnel or clothing (excluding protective clothing) measured (prior to washing or decontamination) in accordance with DOE Radiological Control Manual, Article 338, or equivalent, at a level exceeding the values for total contamination limits identified in 10 CFR 835, Occupational Radiation Protection, Appendix D. The contamination level shall be based on direct measurement and not averaged over any area. For tritium, until a total contamination value is specified by 10 CFR 835 Appendix D, report contaminations exceeding $10,000 \mathrm{dpm} / 100 \mathrm{~cm}^{2}$.

(2) Any occurrence requiring offsite medical assistance for contaminated personnel.

(3) Identification of personnel or clothing contamination offsite due to DOE operations in accordance with approved radiological procedures for determining personnel and/or clothing contamination, measured (prior to washing or decontamination) in accordance with the Radiological Control Manual, Article 338, or equivalent. 


\section{Off-Normal}

(1) Any measurement of personnel or clothing contamination (excluding protective clothing) at a level equal to or exceeding five times the total contamination limits identified in 10 CFR 835, Occupational Radiation Protection, Appendix D, measured (prior to washing or decontamination) in accordance with the DOE Radiological Control Manual Article 338, or equivalent. The contamination level shall be based on direct measurement and not averaged over any area. For tritium, until a total contamination value is specified by 10 CFR 835 Appendix $D$, report contaminations at a level equal to or exceeding 5 times $10,000 \mathrm{dpm} / 100 \mathrm{~cm}^{2}$.

(2) Any measurement of personnel or clothing contamination (excluding protective clothing) at a level exceeding but less than five times the total contamination limits identified in 10 CFR 835, Occupational Radiation Protection, Appendix D, measured (prior to washing or decontamination) in accordance with the DOE Radiological Control Manual Article 338, or equivalent. The contamination level shall be based on direct measurement and not averaged over any area. For tritium, until a total contamination value is specified by 10 CFR 835 Appendix D, report contaminations greater than $10,000 \mathrm{dpm}$ but less than 5 times $10,000 \mathrm{dpm} / 100 \mathrm{~cm}^{2}$.

\section{Group 5 - Safeguards and Security}

Occurrences in this group will require careful review for classified and Unclassified Controlled Nuclear Information, in addition to careful review for privacy considerations. Classified information will be transmitted only through approved communications channels and should be held to the absolute minimum. The lack of detail that may be required in such reports is recognized by DOE management. For the purpose of this group of reportable occurrences, the term "onsite" applies to all facilities, installations, and real property subject to the jurisdiction or administration of the DOE or in its custody and posted with notices of prohibitions and penalties.

A. Criminal Acts Initial notification of events in this section shall follow normal occurrence reporting timelines. When reporting an occurrence that is the subject of an ongoing investigation under this subgroup, the report shall be tailored to prevent jeopardizing the investigation. Full reporting may be delayed until completion of criminal investigations, if the reports would jeopardize the investigation.

\section{Unusual Occurrence}

(1) At DOE reactor or nonreactor nuclear facilities:

(a) bomb-related incidents, including location of a suspicious device or a noncredible bomb threat;

(b) a noncredible terrorist threat; or 
(c) a noncredible sabotage threat or breach/attempted breach of a secure/classified facility.

(2) Violent assault/battery, murder, or unjustified use of deadly force while on DOE property.

(3) Theft/diversion/intentional destruction of Government property valued greater than $\$ 1,000,000$.

(4) Racketeering or other organized criminal activity onsite.

\section{Off-Normal}

(1) At DOE facilities other than reactors and nonreactor nuclear facilities:

(a) location of a suspicious device or noncredible bomb threat;

(b) noncredible terrorist threat; or

(c) noncredible sabotage threat.

(2) Theft/diversion/intentional destruction of government property valued between $\$ 10,000$ and $\$ 1,000,000$.

(3) Onsite felony conspiracies (i.e., blackmail, fraud, embezzlement, extortion and forgery) not involving classified information.

B. Unaccounted for Classified Matter or Compromised Information

\section{Unusual Occurrence}

The loss, potential compromise, or unauthorized disclosure (determined in accordance with DOE M 471.2-1), in any manner, of information classified as, or which should have properly been classified as, Top Secret (all categories) and Secret (all categories), and/or all documents regardless of classification level and category containing Sensitive Compartmented Information, Special Access Program information, and/or classified information of another government agency or foreign government. 


\section{Off-Normal}

The loss, potential compromise, or unauthorized disclosure (determined in accordance with DOE M 471.2-1), in any manner, of information classified as, or which should have properly been classified as, Confidential (all categories), but not including Confidential documents containing Sensitive Compartmented Information, Special Access Program information, and/or classified information of another government agency or foreign government.

C. Substance Abuse

\section{Off-Normal}

Discovery of the prohibited use, possession or involvement of alcohol or illegal drugs by personnel within a facility that may affect facility operations.

(1) Any reportable occurrence under this Manual at least partially attributable to the use of alcohol or illegal drugs.

(2) A detection of personnel not fit for duty attributable to the use of alcohol or illegal drugs.

D. Intelligence Activities

\section{Unusual Occurrence}

(1) Extortion/blackmail directed at DOE or DOE contractor personnel with intent of obtaining classified information/systems, detailed information concerning plant processes/configurations, or aiding in sabotage or terrorist acts.

(2) Espionage, intelligence activities, treason, or subversive activities by or directed at DOE or DOE contractor personnel.

\section{Off-Normal}

(1) When illegal or unauthorized access is sought to classified or sensitive information, technology, or special nuclear materials.

(2) When DOE or DOE contractor personnel believe that they may be the target of an attempted exploitation by an inimical interest, foreign or domestic. 
07-21-97

E. Physical Security System Computer

Unusual Occurrence

(1) Actual/attempted unauthorized access to classified or sensitive unclassified information.

(2) Discovery of a computer incident (virus, hacker, sniffer, abuse, fraud, etc.) involving a physical security system that causes an alteration to a security feature, disruption of service, or loss of the confidentiality, integrity or availability of information, and results in an estimated $\$ 1,000,000$ or more in damages or the cost of restoring services.

\section{Off-Normal}

Discovery of a computer incident (virus, hacker, sniffer, abuse, fraud, etc.) involving a physical security system that causes an alteration to a security feature, disruption of service, or loss of the confidentiality, integrity or availability of information, and results in an estimated $\$ 10,000$ or more in damages or the cost of restoring services.

\section{F. Unplanned/Unscheduled Outage of Site Security System}

\section{Unusual Occurrence}

Unplanned/unscheduled outage of any site security system, or major component of a site security system, that is not redundant and/or results in a potential vulnerability which would allow unauthorized or undetected access to Protected Areas, Exclusion Areas, Material Access Areas, and Sensitive Compartmented Information Facilities.

\section{Off-Normal}

Unplanned/unscheduled outage of any site security system, or major component of a site security system, not encompassed by the Unusual Occurrence category, that is not redundant and not authorized by a facility shutdown plan or a special security plan approved by DOE, that requires the physical presence of the protective force as a compensatory measure to prevent unauthorized access. This does not include the stationing of protective forces as a backup security system identified in a DOE approved facility security plan.

\section{G. Demonstrations/Protests}

\section{Unusual Occurrence}

(1) Disruptive activities impeding vehicular or employees access/egress. 
(2) Attempted or actual trespass.

(3) Malevolent activities causing property damage or bodily harm.

\section{Off-Normal}

Lawful activities warranting deployment of additional protective measures.

H. Firearms

Unusual Occurrence

Unauthorized firearms discharge resulting in personnel injury.

Off-Normal

(1) Unauthorized firearms discharge resulting in no personnel injury.

(2) Loss or theft of DOE firearms or munitions, as per DOE 5632.7A, PROTECTIVE FORCE PROGRAMS. Site specific procedures shall include current amounts identified in DOE 5632.7A.

\section{Other Security Concerns}

\section{Unusual Occurrence}

Unauthorized use, possession, or alteration of a security badge, credential, shield, or other form of official identification (to include blank badge stock/form) to gain access to a protected area or limited area.

\section{Off-Normal}

(1) Discovery of prohibited items within a Protected Area that:

(a) are suspected of being positioned for the purpose of aiding and abetting a malevolent act; or

(b) are, of themselves, illegal.

Items discovered outside controlled areas that are legal under Federal, State, and local laws are not reportable, even if the discovery of such items would otherwise be reportable under this paragraph. 
(2) Onsite death of cleared DOE or DOE contractor personnel by unnatural causes (e.g., suicide, drug overdose).

(3) Loss of security badges in excess of 5 percent in a calendar year.

(4) Onsite malicious mischief, disorderly conduct, or vandalism which disrupts plant activity or causes damage between $\$ 10,000$ and $\$ 100,000$.

J. Material Control and Accountability

\section{Unusual Occurrence}

(1) Loss or apparent loss of the following (including item losses due to shipper-receiver differences):

(a) one or more items for which the items total a Category I, II, or III quantity of special nuclear materials, or

(b) one or more items of tritium in a weapons or test component, or

(c) one or more items which total 50 grams or more of tritium.

(2) An inventory difference (loss or gain) that exceeds alarm limits, does not involve the loss of an item, and is a Category I or II quantity of special nuclear materials.

(3) A shipper-receiver difference involving a gain in the number of items for which the items total to a Category I or II quantity of special nuclear materials.

(4) Evidence that special nuclear material balance or tritium material balance data has been manipulated or falsified to mask a diversion or theft or to alter loss detection sensitivity.

(5) Alarms or other indicators, excluding inventory differences or shipper-receiver differences, from loss detection elements for Category I and II material balance areas that cannot be proven to be false within 24 hours.

(6) Loss or apparent loss whenever a State, local government or other Federal agency must be notified.

\section{$\underline{\text { Off-Normal }}$}

(1) Alarms or other indicators, excluding inventory differences or shipper-receiver differences, from loss detection elements for Category $\mathrm{II}$ and IV material balance areas that cannot be proven to be false within 24 hours. 
(2) A special nuclear materials or tritium inventory difference (loss or gain) that exceeds the alarm limits, does not involve the loss of an item, and is a Category III or IV quantity of material.

(3) A shipper-receiver difference that exceeds 200 grams of fissile material and the combined limit of error for the shipment.

(4) A special nuclear materials or tritium shipper-receiver difference involving a gain in the number of items for which the items total a Category III or IV quantity of material.

(5) Any unexpected accumulation of fissile material within primary confinement boundaries.

(6) A statistically significant trend in total inventory difference for special nuclear materials or tritium inventories.

(7) Loss or apparent loss of one or more items for which the items total a Category IV quantity of special nuclear materials or any loss of one or more containers of tritium that does not meet the threshold for an Unusual Occurrence (includes item losses due to shipper-receiver differences).

\section{Group 6 - Transportation}

Transportation of DOE Hazardous Materials. Transportation occurrences are incidents related to the transportation of DOE materials, including hazardous materials, hazardous substances, and hazardous wastes by vehicular, vessel, air, or rail mode. The requirements for reporting noncompliances and violations associated with such transfers are qualified in this Manual. The Federal regulations for offsite transportation are found in 10 CFR Part 71, 49 CFR Parts 106-180, 200-250, and 350-399, 46 CFR (vessel), ICAO/IATA, IMDG, 14 CFR (aviation), and several DOE Orders. For onsite (within controlled boundaries of DOE facilities), the transportation regulations for hazardous materials transfers are the same as offsite (DOT's Hazardous Materials Regulations) or as defined in an approved facility Transportation Safety Document.

DOE facilities receiving materials from a DOE shipper that are not in compliance with appropriate regulations, as qualified by this Manual, must report the discrepancies to the DOE shipper who will prepare an Occurrence Report and implement suitable corrective actions. If such a shipment is received from a non-DOE shipper and meets the reporting criteria of this Manual, the DOE organization will notify the non-DOE shipper of the apparent noncompliance and will prepare an Occurrence Report stating that the non-DOE shipper has been notified. These reporting criteria are in addition to any required by DOT for contractors subject to the DOT regulations. 


\section{Unusual Occurrence}

(1) Any packaging or transportation activity (including loading, unloading, or temporary storage) involving the offsite release of radioactive material, etiologic agents, a reportable quantity of hazardous substance, or marine pollutants.

(2) Any shipment of radioactive material that arrives at its destination with radiation or contamination levels greater than DOT limits, or results in personnel radiation exposure higher than permitted in Federal permits, Federal regulations, or DOE standards.

(3) Any shipment or onsite transfer of radioactive material or hazardous waste that arrives at its destination with an unaccounted for package or an irreconcilable shipping paper, waste manifest, or onsite transfer authorization.

(4) A vehicle, vessel, rail or air incident or accident (without personal injury) that presents significant impact on the ability of a facility to conduct transportation operations and:

(a) results in release of radioactive or hazardous materials above Federal permit, Federal regulatory, or DOE Standard limits;

(b) involves performance degradation of safety equipment; or

(c) is the result of failure or degradation of administrative controls required to ensure safety.

(5) Violations of the Federal Motor Carrier Safety Regulations or the Hazardous Materials Regulations if those violations are determined by DOT inspection and result in a fine (monetary penalty).

\section{Off-Normal}

(1) Any packaging or transportation activity involving:

(a) the offsite release of non-radioactive hazardous material, or any quantity of hazardous waste; or

(b) the onsite release of radioactive materials, etiologic agents, hazardous substances, hazardous waste, or marine pollutants. 
(2) A vehicle, vessel, rail or air incident or accident (without personal injury) that affects the ability of a facility to conduct transportation operations and:

(a) results in release of radioactive or hazardous materials below limits established by Federal permits, Federal regulations, or DOE Standard limits but must be reported to State or local agencies; or

(b) is the result of operational procedural violations, including maintenance or administrative procedures.

(3) Noncompliances (potential violations) of the DOT Hazardous Materials Regulations or the transportation and packaging requirements of the Nuclear Regulatory Commission involving:

(a) errors made by the shipper in materials description, marking, labeling, or placarding;

(b) an unqualified person signing shipping papers;

(c) the highway routing selection requirements for highway route controlled shipments or the notification requirements for spent-fuel shipments not being observed;

(d) the separation and segregation tables for hazardous materials not strictly adhered to; or

(e) the applicable packaging requirements for the assembly, handling, or selection of a package not being in accordance with the applicable regulations.

(4) Noncompliances (potential violations) of the Federal Motor Carrier Safety Regulations involving:

(a) a contractor driver operating a DOE-owned motor vehicle after a positive drug test or failure of an alcohol test;

(b) an unqualified driver operating a vehicle (medical, driver's license, or training not in compliance);

(c) the carrier (contractor management) not having required insurance;

(d) a vehicle that failed inspection not being removed from service;

(e) a specification cargo tank with expired inspection being in service with hazardous materials; 
(f) a driver's log book deliberately misrepresented; or

(g) the carrier (contractor management) failing to perform random or periodic drug or substance-abuse testing.

(5) Any violation of the Hazardous Material Regulations or Federal Motor Carrier Safety Regulations if that violation is determined by DOT inspection and does not result in a penalty.

\section{Group 7 - Value Basis Reporting}

Value basis reporting includes items based on cost or the identification of defective items, materials, or services. A defective item, material, or service (see definition) shall be identified and reported to allow the initiation of a Headquarters investigation and make all Departmental Elements aware of the defect and initiate actions to eliminate common mode failures due to substandard, counterfeit, misrepresentation, or fraudulent practices of suppliers.

A. Cost Based Occurrences Any occurrence specifying cost as a basis for reporting, unless otherwise stated, will be classified by the following monetary values necessary to repair, replace, or otherwise restore a facility/system/component to acceptable operation. Costs used for reporting should be reasonable initial estimates.

\section{Unusual Occurrence}

Estimated loss or damage to DOE or other property amounting to $\$ 1,000,000$ or more, or estimated costs of $\$ 1,000,000$ or more required for cleaning (including decontamination), renovating, replacing, or rehabilitating structures, equipment, or property.

\section{Off-Normal}

Estimated loss or damage to DOE or other property amounting to between $\$ 10,000$ and $\$ 1,000,000$ (for vehicle/aircraft the lower limit is $\$ 5,000$ or, for insurance purposes, considered a total loss) or estimated costs within these limits required for cleaning (including decontamination), renovating, replacing or rehabilitating structures, equipment, or property.

B. Defective Item, Material, or Service

\section{Off-Normal}

(1) Discovery of any actual or potential defective item, material, or service, including any suspect, counterfeit, or substandard product, in any application whose failure could result in a substantial safety hazard. Examples include the identification of suspect, counterfeit or substandard products found in: 
(a) cranes, elevators, and fork lifts - items used in the critical load bearing path of such handling and lifting equipment;

(b) aircraft - items used in engines or to attach engines, wings, tails, or landing gear;

(c) vehicles - items used in engines, brakes or steering mechanisms;

(d) critical components used in personnel safety equipment; and

(e) facilities -

1. items used to contain:
a. radioactive fluids
b. high temperature or pressure steam or fluids, or
c. other hazardous material

2. Safety Class SSC or Safety Significant SSC supporting the safe operation or shutdown of a facility, system, or process that could result in a performance degradation.

Guidance in the identification and follow-up actions are contained in DOE Quality Alerts or other bulletins.

(2) Discovery of any actual or potential defective item, material, or service, including any suspect, counterfeit, or substandard product, in any application whose failure could not result in a substantial safety hazard. This does not include office supplies, equipment, or household products.

\section{Group 8 - Facility Status}

This section involves the change of facility status that may affect the performance goals of a facility. The potential inability to meet performance goals may significantly affect other major and minor facilities throughout the complex. Performance goals are operating objectives necessary to accomplish an approved facility, process, or activity mission on a periodic basis. The duration of the goal may be short or long term, but should not exceed the goals of the annual operating plan. 
DOE M 232.1-1A

07-21-97

A. Facility/Process/Activity Unscheduled Shutdown

Off-Normal

Any unscheduled shutdown of a facility, process, or activity that resulted or may result in the failure to meet approved performance goals.

B. Existing Facility/Process/Activity Shutdown Extension

\section{Off-Normal}

Any increase in an approved shutdown schedule of 1 month or greater or that resulted or may result in the failure to meet approved performance goals for an existing facility, process, or activity.

C. New Facility/Process/Activity Start-up Delay

\section{Off-Normal}

Any delay in an approved start-up schedule of 1 month or greater and which resulted or may result in the failure to meet approved performance goals for a new facility, process, or activity.

\section{Group 9 - Nuclear Explosive Safety}

Any nuclear explosive occurrence at DOE facilities or during onsite or offsite nuclear explosive transportation.

\section{Unusual Occurrence}

(1) The unauthorized introduction of electrical energy into a nuclear explosive.

(2) The unauthorized compromise of a nuclear explosive safety feature when installed on a nuclear explosive.

(3) Damage to a nuclear explosive that results in a credible threat to nuclear explosive safety.

(4) Inadvertent substitution of a nuclear explosive for a nuclear explosive-like assembly (NELA) or vice versa.

(5) A violation of a nuclear explosive safety rule (NESR). 


\section{Off-Normal}

(1) A "near miss", i.e., a situation that could (but did not) result in a credible threat to nuclear explosive safety.

(2) A violation of the two-person concept of operations.

(3) Revocation of the Personnel Assurance Program (PAP) certification of an individual (for cause).

(4) Damage to a training unit during training operations indicative of a hazard to a nuclear explosive.

(5) The use of uncertified personnel or unauthorized equipment/tooling during a nuclear explosive operation.

\section{Group 10 - Cross-Category Items}

\section{A. Collectively Significant Related Occurrences}

\section{Unusual Occurrence}

A series of related occurrences which individually do not warrant reporting under preceding criteria but which collectively are considered significant enough to warrant reporting as determined by the Facility Manager.

\section{Off-Normal}

A series of related occurrences which individually do not warrant reporting under preceding criteria but which collectively are considered significant enough to warrant reporting as determined by the Facility Manager.

\section{B. Near Miss Occurrences}

\section{Unusual Occurrence}

A near miss to one of the reporting classifications under preceding categories where the conditions necessary to cause an Unusual Occurrence existed (i.e., all barriers to event initiation were compromised). 
Off-Normal

(1) A near miss to one of the reporting classifications under preceding categories where the conditions necessary to cause an Off-Normal Occurrence existed (i.e., all barriers to event initiation were compromised).

(2) A near miss to one of the reporting classifications under preceding categories where the conditions necessary to cause a reportable occurrence were prevented from existing by one remaining barrier after other barriers had been compromised (i.e., one additional independent failure/degradation was necessary for event initiation to be possible).

\section{Potential Concerns/Issues}

\section{Unusual Occurrence}

(1) An occurrence that may result in a significant concern, by the press or general population, particularly in the offsite transportation and radiological areas, or could damage the credibility of the Department.

(2) Identification of potential concerns or issues that are deemed to be worthy of reporting by the Facility Manager.

\section{Off-Normal}

(1) Any event resulting in the initiation of a Type A or B investigation as categorized by DOE $O$ 225.1, ACCIDENT INVESTIGATIONS.

(2) Identification of potential concerns or issues, that are deemed to be worthy of reporting by the Facility Manager

\section{INSTRUCTIONS FOR COMPLETING AN OCCURRENCE REPORT.}

\subsection{General}

The following instructions apply to the reporting of occurrences via hard copy or the electronic data base, the Occurrence Reporting and Processing System (ORPS). All reports containing classified information or Unclassified Controlled Nuclear Information (UCNI) shall be submitted in hard copy in accordance with established security requirements. An unclassified, nonsensitive version shall be submitted to ORPS for entry into the data base.

The numbers on the specific report items correspond with the numbers in the Occurrence Report format. All fields with an asterisk (*) preceding them are required 
for all (notification, update, and final) reports. Fields marked with a pound sign (\#) are required under certain conditions, for example, depending on occurrence type, report type, or the answer to a previous question.

Items 1 through 19 and Item 25 of the Occurrence Report are required for the Notification Report. Data shall be entered in all other fields when known. For the Update Report and Final Reports, information on the Notification Report shall be retained and updated as better information becomes available. The Facility Representative and Program Manager may provide comments in Items 34 and 35, respectively, for all reports.

\subsection{Occurrence Report Items}

A. Facility/Personnel Information

(1) *Name of Facility. Enter the name of the facility where the occurrence took place.

(2) *Facility Function. Enter the type of facility or the activity/function performed by the facility. Only one function can be selected. Possible entries are listed below.

01 - Plutonium Processing and Handling

02 - Special Nuclear Materials Storage

03 - Explosive

04 - Uranium Enrichment

05 - Uranium Conversion/Processing and Handling

06 - Irradiated Fissile Material Storage

07 - Reprocessing

08 - Nuclear Waste Operations/Disposal

09 - Tritium Activities

10 - Fusion Activities

11 - Environmental Restoration Operations

12 - Category "A" Reactors

13 - Category "B" Reactors

14 - Solar Activities

15 - Fossil and Petroleum Reserves

16 - Accelerators

99 - Balance-of-Plant (e.g., offices, machine shops, site/outside utilities, safeguards/security, and transportation)

(3) *Name of Laboratory, Site, or Organization. Enter the name of the laboratory, site, or organization. If ORPS is being used, the laboratory, 
site, or organization and the name of the DOE contractor for the facility will be automatically provided by the computer.

(4) *Facility Manager/Designee. Enter the name, title, and telephone number of the Facility Manager or designee who has direct line responsibility for operation of the facility. If ORPS is being used, enter the name, title, and telephone number of the responsible Facility Manager or designee who approved this report, either by personally transmitting the electronic report or by signing the hard copy report. NOTE: ORPS will not automatically enter the name of the Facility Manager in this field.

(5) * Originator/Transmitter. Enter the name, title, and telephone number of the person who originated this report. This is the person who gathers the information and is most knowledgeable about the event. If ORPS is being used, the name of the transmitter will automatically be entered by the computer when the report is uploaded. If there is not a signed, hard copy Final Report on file, the report must be transmitted by the Facility Manager or designee.

(6) \#Authorized Classifier. For facilities where classified operations are conducted and classified information is generated, enter the name of the Authorized Classifier who determined that the report was unclassified and the date of the determination.

B. Specific Report Items.

(1) * Occurrence Report Number. Enter an alphanumeric designation that identifies the DOE Field Office, Area Office (if applicable), DOE contractor or laboratory involved, facility, the calendar year of the occurrence, and sequential number of the occurrence by facility. If ORPS is being used, the Occurrence Report number will be automatically generated. Examples are SR--WSRC-MED-1995-0005 and AL-AO-MHSM-PANTEX-1995-0003.

(2) * Report Type and Date. Check the block that identifies the type of Occurrence Report being submitted. Use an Update Report for recategorization of an occurrence. Possible entries are Notification Report, Update Report, or Final Report.

(a) Items 1 through 19 and Item 25 of the Occurrence Report are required for the Notification Report, which remains a part of subsequent Occurrence Reports.

All dates and the time of the Notification Report submission are 
computer generated. The date that the report is entered into the ORPS data base is the Occurrence Report's submission date.

(c) For hard copy reports, show all dates. That is, for a Final Report, this block must show the submission dates of the Notification Report, latest Update Report, and Final Report.

(d) To cancel an Occurrence Report, check the block under Report Type for Final Report as well as the block for canceled under occurrence category (Item 3 below). Canceled reports must be finalized and go through the same approval process as all other Occurrence Reports; however, Items 20 through 35 are not required fields for canceled reports and, once it is signed by the Facility Representative and Program Manager, the Occurrence Report will be removed from the active data base.

(3) * Occurrence Category. Indicate which category has been determined for the occurrence. Only one category can be selected. Possible entries are Emergency, Unusual, Off-Normal, Canceled.

(4) *Number of Occurrences. Enter the number of occurrences included in this report. The number will always be one unless the occurrences meet the specific criteria for Roll-Up Reports for Off-Normal Occurrences, as discussed in Section 5.7. If the occurrences meet those criteria, be sure to change this field each time additional occurrences are added.

\#Original Occurrence Report Number. For Roll-Up Reports with an approved Final Report, enter the Occurrence Report number for the original occurrence that is in the ORPS data base as an approved Final Report.

(5) *Division or Project. Identify the project or the contractor organization responsible for the facility at which the occurrence took place. 
(6) *DOE Secretarial Office. Identify the DOE Secretarial Office to which this facility is operationally responsible. Only one Secretarial Office can be selected. If the facility is operationally responsible to more than one Secretarial Office, enter the Secretarial Office that is most directly involved in the specific work activity during which the occurrence took place. Possible entries are listed below.

DP - Defense Programs

EE - Energy Efficiency and Renewable Energy

$\mathrm{EH}$ - Environment, Safety and Health

EI - Energy Information Administration

EM - Environmental Management

ER - Energy Research

FE - Fossil Energy

HR - Human Resources and Administration

NE - Nuclear Energy, Science and Technology

NN - Nonproliferation and National Security

RW - Civilian Radioactive Waste Management

(7) * System, Building, or Equipment. Identify the systems, equipment, or structural items involved in the occurrence, as applicable. In addition, in the case of component failures or defective parts or materials, provide such information as the manufacturer, model number, and size. The most significant item(s) should be listed here. Additional information can be provided in the Description of Occurrence (Item 16).

(8) *Unclassified Controlled Nuclear Information. For facilities where UCNI is generated, a reviewing official shall make a final determination that the report contains (enter "Y" for Yes) or does not contain (enter "N" for No) UCNI. Reports containing UCNI shall not be entered into the ORPS data base. A nonsensitive version shall be entered into the ORPS data base within the required time frames.

(9) \#Plant Area. Indicate the name of the site-specific plant area (e.g., F-Area, M-Area) where the occurrence took place.

(10) *Date and Time Occurrence Was Discovered. Enter the date and time when the facility staff discovered the event or condition being reported. 
(11) *Date and Time Occurrence Was Categorized. Enter the date and time the Facility Manager determined that the event or condition constituted a reportable occurrence and determined its category (Emergency, Unusual, or Off-Normal Occurrence).

(12) \#DOE HQ Oral Notification. Enter the name of the DOE HQ EOC Coordinator and the date and time when the DOE HQ EOC was notified. This field is not required for occurrences that are categorized as off-normal.

(13) \#Other Notifications. Enter the name(s), organization(s), date(s), and notification time(s) of State and local officials or other agencies. Additional information can be provided in the Immediate Actions Taken and Results field (Field\# 19).

(14) * Subject or Title of Occurrence. Enter a brief title or description (140 characters or less) of the nature, cause, and result of the occurrence. If the occurrence involved an Unreviewed Safety Question, the acronym "USQ" shall be placed at the end of the Subject or Title of Occurrence. If the report is a Roll-Up Report, include "Roll-Up" in the title.

(15) *Nature of Occurrence. Enter the nature(s) of the occurrence as discussed in Section 9 of this Manual. As many as three selections can be made.

Possible entries are listed below.

Group 1. Facility Condition

$01 \mathrm{~A}$ - Nuclear Criticality Safety

01B - Fires/Explosions

01C - Safety Status Degradation

01D - Loss of Control of Radioactive Material/Spread Contamination

01E - Safety Structure/System/Component Degradation

01F - Violation/Inadequate Procedures

$01 \mathrm{G}$ - Oversight Activities

$01 \mathrm{H}$ - Operations

Group 2. Environmental

$02 \mathrm{~A}$ - Radionuclide Releases

02B - Release of Hazardous Substances/Regulated Pollutants/Oil

02C - Hazardous Material Contamination

02D - Ecological Resources

02E - Environmental Agreement/Compliance Activities 


\author{
Group 3. Personnel Safety \\ 03A - Occupational Illness/Injuries \\ 03B - Vehicular Incidents \\ 03C - Safety Concerns
}

Group 4. Personnel Radiological Protection

04A - Radiation Exposure

04B - Personnel Contamination

Group 5. Safeguards and Security

05A - Criminal Acts

05B - Unaccounted for Classified Matter/Compromised Information

05C - Substance Abuse

05D - Intelligence Activities

05E - Physical Security System Computer

05F - Unplanned/Unscheduled Outage of Site Security System

$05 G$ - Demonstrations/Protests

05H - Firearms

05I - Other Security Concerns

05J - Material Control and Accountability

Group 6. Transportation

Group 7. Value Basis Reporting

07A - Cost Based Occurrences

07B - Defective Item, Material, or Service

Group 8. Facility Status

08A - Facility/Process/Activity Unscheduled Shutdown

08B - Existing Facility/Process/Activity Shutdown Extension

08C - New Facility/Process/Activity Start-up Delay

\section{Group 9. Nuclear Explosive Safety}

Group 10. Cross-Category Items

10A - Collectively Significant Related Occurrences

10B - Near Miss Occurrences

10C - Potential Concerns/Issues

(16) *Description of Occurrence. Enter a clear, concise, objective description of what happened and what was observed. To the maximum extent possible, a sequence of events should be provided. The type of information to be provided in the description includes all of, but is not limited to, the following: 
a. The method of discovery.

b. Any component failures and the failure modes.

c. Any personnel errors involved, including the type and result of the error.

d. Any procedure problem encountered.

e. The response of any automatic or manual safety systems and the signals which initiated and terminated their operation.

f. The duration of any failures.

g. Operator actions that affected the course of events.

h. The loss of any safety equipment.

i. For contamination events, the information described in Sections 10.3.1.a and 10.3.2.a.

When appropriate for clarification, photos, sketches, or drawings should be attached. Other documents such as investigation reports, Notices of Violation (NOVs), environmental enforcement action, and formal root cause analysis reports should also be attached. If ORPS is used, all photos, sketches, or drawings should be referenced as attachments to the Occurrence Report, with specifics as to where or from whom they can be obtained.

To the extent possible, avoid the use of plant-specific terms and acronyms. When used, such terms should be clearly defined.

(17) *Operating Conditions of Facility at Time of Occurrence. Describe the operational status of the facility or equipment at the time of the occurrence including, for example, pertinent temperatures, pressures, or other parameters necessary for evaluation of the occurrence and its consequences. If said information is not applicable, enter "Does not apply."

(18) *Activity Category. Enter one of the following activities that best describes the ongoing activity at the time of the occurrence.

01 - Construction

02 - Maintenance

03 - Normal Operations

04 - Start-up

05 - Shutdown

06 - Facility/System/Equipment Testing

07 - Training

08 - Transportation

09 - Emergency Response

10 - Inspection/Monitoring

11 - Facility Decontamination/Decommissioning 
(19) *Immediate Actions Taken and Results. Describe the immediate or remedial actions taken to return the facility, system, or equipment item to service; to correct or alleviate the anomalous condition; and to record the results of those actions. These may include temporary measures to keep the facility in a safe standby condition or to permit continued operation of the facility without compromising safety until a more thorough investigation or permanent solution can be effected. For contamination events, include the information described in 10.3.1.b and 10.3.2.b.

(20)-(22) \#Cause. This must be thoroughly addressed as the information becomes available. Enter the cause(s) that best describes the apparent root, direct and contributing cause(s), if applicable. Only one direct and root cause may be entered, but up to three contributing causes may be entered. In the final evaluation of a reportable occurrence, there must be complete consideration of the cause, including contributory factors, with analysis to show what cause was root to the occurrence and what causes were only contributory. In conducting evaluations of the occurrence to determine the root cause, the critiques and analyses described in DOE-NE-STD-1004-92 should be used. The possible entries are the same for all three cause fields. The direct, contributing, and root causes of reportable occurrences are classified into eight broad categories and various subcategories. The eight categories of causes and their associated subcategories are as follows:

1 - Equipment/Material Problem. An event or condition resulting from the failure, malfunction, or deterioration of equipment or parts, including instruments or material.

1A - Defective or Failed Part. A part/instrument that lacks something essential to perform its intended function.

1B - Defective or Failed Material. A material defect or failure.

1C - Defective Weld, Braze, or Soldered Joint. A specific weld/joint defect or failure.

1D - Error by Manufacturer in Shipping or Marking. An error by the manufacturer or supplier in the shipping or marking of equipment.

$1 \mathrm{E}$ - Electrical or Instrument Noise. An unwanted signal or disturbance that interferes with the operation of equipment.

$1 \mathrm{~F}$ - Contaminant. Failure or degradation due to radiation damage or foreign material such as dirt, crud, or impurities. 
$1 \mathrm{G}$ - End of Life Failure. A failure where the equipment or material is run to failure and has reached its end of design life.

2 - Procedure Problem. An event or condition that can be traced to the lack of a procedure, an error in a procedure, or a procedural deficiency or inadequacy.

$2 \mathrm{~A}$ - Defective or Inadequate Procedure. A procedure that either contains an error or lacks something essential to the successful performance of the activity.

2B - Lack of Procedure. No written procedure was in place to perform the activity.

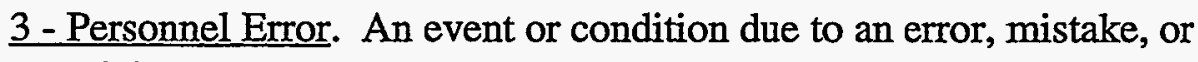
oversight.

$\underline{3 A}$ - Inattention to Detail. Inadequate attention to the specific details of the task.

3B - Procedure Not Used or Used Incorrectly. The failure to use or the inappropriate use of written instructions, procedures, or other documentation.

3C - Communication Problem. Inadequate presentation or exchange of information.

3D - Other Human Error. Human error other than those described above.

4 - Design Problem. An event or condition that can be traced to a defect in design or other factors related to configuration, engineering, layout, tolerances, calculations, etc.

4A - Inadequate Work Environment. Inadequate design of equipment used to communicate information from the facility to a person (e.g., displays, labels, etc.) as well as inadequate work environment, such as inadequate lighting, working space, or other human factor considerations.

4B - Inadequate or Defective Design. A design in which something essential was lacking (defective) or when a detail was included but was not adequate for the requirement (inadequate). 
4C - Error in Equipment or Material Selection. A mistake in the equipment or material selection only, not to include a procurement error (see Personnel Error - (e) Other Human Error) or a specification error (see Design Problem - (d) Drawing, Specification, or Data Errors).

4D - Drawing, Specification, or Data Errors. An error in the calculation, information, or specification of a design.

5 - Training Deficiency. An event or condition that can be traced to a lack of training or insufficient training to enable a person to perform a desired task adequately.

$\underline{5 A}$ - No Training Provided. A lack of appropriate training.

5B - Insufficient Practice or Hands-On Experience. An inadequate amount of preparation before performing the activity.

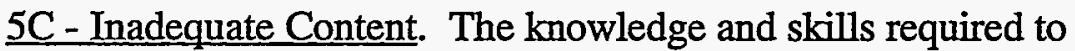
perform the task or job were not identified.

5D - Insufficient Refresher Training. The frequency of refresher training was not sufficient to maintain the required knowledge and skills.

5E - Inadequate Presentation or Materials. The training presentation or materials were insufficient to provide adequate instruction.

6-Management Problem. An event or condition that can be directly traced to managerial actions or methods.

6A - Inadequate Administrative Control. A deficiency in the controls in place to administer and direct activities.

6B - Work Organization/Planning Deficiency. A deficiency in the planning, scoping, assignment, or scheduling of work.

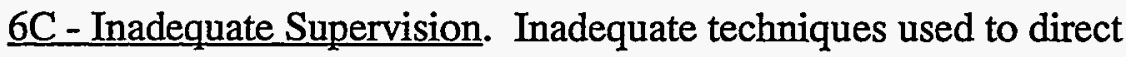
workers in the accomplishment of tasks.

6D - Improper Resource Allocation. Improper personnel or material allocation resulting in the inability to successfully perform assigned tasks. 
6E-Policy Not Adequately Defined, Disseminated, or Enforced. Inadequate description, distribution, or enforcement of policies and expectations.

6F - Other Management Problem. A management problem other than those defined above.

7 - External Phenomena. An event or condition caused by factors that are not under the control of the reporting organization or the suppliers of the failed equipment or service.

7A - Weather or Ambient Condition. Unusual weather or ambient conditions, including hurricanes, tornadoes, flooding, earthquake, and lightning.

7B - Power Failure or Transient. Special cases of power loss that are attributable to outside supplied power.

7C - External Fire or Explosion. An external fire, explosion, or implosion.

7D - Theft. Tampering, Sabotage or Vandalism. Theft, tampering, sabotage, or vandalism that could not have been prevented by the reporting organization.

8 - Radiological/Hazardous Material Problem. An event related to radiological or hazardous material contamination that cannot be attributed to any of the other causes.

8A - Legacy Contamination. Radiological or hazardous material contamination attributed to past practices.

8B - Source Unknown. Radiological or hazardous material contamination where the source cannot be reasonably determined.

Specific information pertaining to each cause Field, \#(20), (21), and (22), is as follows.

(20) \#Direct Cause. The cause that directly resulted in the occurrence. Enter only one direct cause for the occurrence. One subcategory for the direct cause selected must also be checked. The direct cause is not required for Update Reports; however, it is required for Final Reports. 
For example, in the case of a leak, the direct cause could have been the failure in the component or equipment that leaked. In the case of a system misalignment, the direct cause could have been operator error in the alignment.

(21) Contributing Causes. The cause(s) that contributed to the occurrence but, that by itself, would not have caused the occurrence. Enter as many as three contributing causes for the occurrence. One subcategory for each of the contributing causes must also be checked. This is not a required field.

For example, in the case of a leak, the contributing cause could be lack of adequate operator training in leak detection and response resulting in a more severe event than would have otherwise occurred. In the case of a system misalignment, the contributing cause could be excessive distractions to the operators during shift, resulting in less than adequate attention to important details during system alignment.

(22) \#Root Cause. The cause that, if corrected, would prevent recurrence of this and similar occurrences. The root cause does not apply to this occurrence only, but has generic implications to a broad group of possible occurrences, and it is the most fundamental aspect of the cause that can logically be identified and corrected. There may be a series of causes that can be identified, one leading to another. This series should be pursued until the most fundamental, correctable cause has been identified. Check only one root cause for the occurrence. One subcategory for the root cause selected must also be checked. The root cause is not required for Update Reports; it is, however, required for Final Reports.

For example, in the case of a leak, the root cause could be a failure of management to ensure that maintenance is effectively managed and controlled. This cause could have led to the use of improper seal material or missed preventive maintenance on a component, which ultimately led to the failure. In the case of a system misalignment, the root cause could be failure in the training program, leading to a situation in which operators are not fully familiar with control room procedures and are willing to accept excessive distractions.

(23) \#Description of Cause. Discuss the cause of the occurrence to include root, direct, and contributing causes, if applicable, and the corrective actions identified. Do not repeat a description of the occurrence but discuss the results of the causal analysis. The root cause analysis methodology used shall be identified. A detailed description of the corrective actions is required to demonstrate that the identified actions will adequately address the cause(s) of the problem. 
For example, if a procedural deficiency was identified, it would not be sufficient to state simply that the procedure was revised. An explanation is required regarding why the deficiency was not identified during the review and approval process (to the extent possible); how the procedure was subsequently revised; and how the revision, in conjunction with any other corrective actions, addresses the cause of the problem.

When appropriate, separate documentation for the root cause analysis may be attached. If ORPS is being used, the separate documentation should be referenced as attachments to the Occurrence Report, with specifics as to where or from whom they can be obtained.

Reports of suspect/counterfeit products (Group 7B) shall include the text suspect/counterfeit products in this section to facilitate searches.

This field is not required for Update Reports; it is, however, required for Final Reports.

(24) \#Evaluation by Facility Manager. With the information available, the Facility Manager should provide his or her evaluation of the occurrence and its effect or possible effect on the plant, system, program, etc. in the Update Report. The Facility Manager may later supplement this evaluation with additional entries in Update Reports or in the Final Report. This field is required on a Notification Report if the responses to Item 25, Is Further Evaluation Required, are "Yes," further evaluation is required, and "Yes," the evaluation is required before further operation. 
(25) *Is Further Evaluation Required? Check "Yes" or "No." This is a required field on all reports. This response should not be "Yes" in a Final Report since further evaluation could change the root cause or identify additional corrective actions.

If further evaluation is required, then "Yes" or "No" must be checked as to whether that evaluation is required before further operation.

If further evaluation is required before further operation (i.e., both "Yes" blocks checked), then who will take the action (a person's title or a specific organizational unit) and a date when the action will be taken must be provided. Field \# 24 should be completed if "Yes" is checked in both blocks.

(26) \#Corrective Actions. List all actions identified to correct the problem that, when completed, will prevent recurrence. The first two lines of each corrective action should be a title or summary of the corrective action. In addition, provide actual or target completion dates for all of the corrective actions listed.

For similar occurrences previously documented in an approved Final Report (as discussed in Section 5.7.2), the corrective action narrative should state, "The corrective actions are the same as those stated in the original approved Final Report" and provide the original approved Final Report number; the corrective action target date should be the latest target date on the original approved Final Report; and the corrective action completion date should be the final actual completion date for all of the corrective actions (i.e., the field will remain empty until completion of all of the corrective actions).

This field is not required for Update Reports; however, it is required for Final Reports.

(27) \#Impact on Environment, Safety, and Health. Provide an assessment of the environment, safety, and health consequences and implications of the occurrence. Describe the impact of the occurrence on the environment, safety, and health of workers, the public, and onsite/offsite environs. This should include amounts and types of hazardous or radioactive materials released, levels and types of contamination, exposure levels of workers and the public, and known or projected environmental, safety, and health impacts. This assessment may be based on existing conditions. The evaluation must be carried out to the extent necessary to fully assess the safety consequences and safety margins associated with the occurrence.

For an occurrence related to nuclear safety, an assessment of the occurrence 
under alternative conditions must also be included if the occurrence could have been more severe (e.g., the facility would have been in a condition not analyzed in the Safety Analysis Report) under reasonable and credible alternative conditions such as power level or operating mode. For example, if the occurrence happened while the facility was at 15 percent power and the same occurrence could have taken place while the facility was at 100 percent power, and, as a result, the environment, safety, or health consequences would have been considerably more serious, the assessment must describe those conditions and consequences.

For contamination events, include the information described in Sections 10.3.1.c and 10.3.2.c.

This field is not required for Update Reports; it is, however, required for Final Reports.

(28) \#Programmatic Impact. Describe the impact of the occurrence on the program or project affected. This could be a loss of data, loss of plant availability for a specified period, additional costs, schedule delays, or other measurable consequences of the occurrence.

This field is not required for Update Reports; it is, however, required for Final Reports.

(29) \#Impact Upon Codes and Standards. If the occurrence affects the requirements of national codes and standards, program standards, or DOE Orders, a statement regarding the adequacy of the codes or standards should be provided, along with any recommended changes.

This field is not required for Update Reports; it is, however, required for Final Reports.

(30) \#Lessons Learned. Include any lessons learned from the occurrence that could be of importance to other facility operators or that should be addressed in personnel training or facility procedures.

This field not required for Update Reports; it is, however, required for Final Reports. 
(31) \#Similar Occurrence Report Numbers. Indicate by their report numbers any similar occurrence(s) of which you are aware for this or other facilities. Also, identify any known commercial reactor Licensee Event Reports or other related documents that describe similar occurrences. The purpose of this item is to identify, if recognized, occurrences that might suggest a generic problem that may result in single or common lessons learned.

This field not required for Update Reports; it is, however, required for Final Reports.

(32) User-defined Field \#1. This optional field can be used by the Facility Manager to store facility-specific information (e.g., a cross-reference to performance indicator data).

(33) User-defined Field \#2. This optional field can be used by the Facility Manager to store additional facility-specific information (e.g., a crossreference to a site-specific number or name).

(34) \#Facility Representative Input. The Facility Representative or designee should provide his or her evaluation of the occurrence, including an evaluation of the initial and proposed corrective actions and any follow-up by the facility personnel, and should describe any other actions that DOE has taken since the occurrence. The Facility Representative may supplement such information with subsequent additional entries, as appropriate. After completing the input, enter the Facility Representative's name and the date. If ORPS is being used, the Facility Representative's name and the date will be automatically entered by the computer. If a Final Report is being rejected, the Facility Representative shall use this space to indicate why.

This field is required only on Final Reports rejected by the Facility Representative.

(35) \#Program Manager Input. The Program Manager or designee should provide his or her evaluation of the occurrence, including an evaluation of the initial and proposed corrective actions and any follow-up, and should describe any other actions that DOE has taken since the occurrence. The Program Manager may include additional entries as appropriate. After completing the input, enter the Program Manager's name and the date. If ORPS is being used, the Program Manager's name and the date will be automatically entered by the computer. If a Final Report is being rejected, the Program Manager shall use this space to indicate why. If the approval authority for Off-Normal reports has been delegated to the Facility Representative, then the Program Manager will only be able to provide 
comments on the Off-Normal Final Report prior to approval of the report by the Facility Representative.

This field is required only on Final Reports rejected by the Program Manager.

(36) \#Signatures. For Final Reports that are transmitted in hardcopy (i.e., classified or UCNI reports), all three signatures, with typed names and titles, shall be included prior to distribution. If ORPS is being used, the Facility Manager's or designee's name, as described and entered in Item 4 of Section 10.2.A, will automatically be entered with an indication of acceptance. The Final Report will then be available for the Facility Representative and Program Manager, or their designees, to review and accept. Once all three individuals have accepted the report, it will automatically be available to all DOE Elements for their use in analysis and trending. This field is required for Final Reports only.

\subsection{Reporting Radiological Contamination Occurrences}

The information provided on the following pages provides guidance for completing an Occurrence Report under Group 1D or Group 4B of this Manual.

The information provided for the following items, 16, "Description of Contamination Occurrence;" 19,"Immediate Action in Response to Contamination Occurrence;" and 27, "Impact on Worker Health Due to Contamination Occurrence," should be completed or reviewed by qualified radiological control personnel (i.e., the Radiological Control Manager, health physicists, qualified radiological control technicians, or supervisory personnel). The health consequence (i.e., severity or significance) of the contamination occurrence is specified in Item 27 of an Occurrence Report.

Where the information regarding an occurrence is preliminary, the notification of such occurrences should be prefaced with remarks to the effect that:

"The contamination occurrence is based on preliminary information available at the time of the report. This information will be updated when further evaluation has been completed." 


\subsubsection{Personnel Contamination Occurrences}

\begin{tabular}{|c|c|c|}
\hline 10.3.1.a & \multicolumn{2}{|r|}{ Description of Contamination Occurrence - Item 16} \\
\hline Type of information & & Suggested statements \\
\hline Number and types of individuals & $\begin{array}{l}\text { a. } \\
\text { b. } \\
\text { c. }\end{array}$ & $\begin{array}{l}\text { Contamination event involves single individual. } \\
\text { Contamination event involves } \_ \text {individuals. } \\
\text { Type of individual: radiation worker, general employee, member of the public, minor, visiting } \\
\text { scientist or researcher, visiting DOE or other Federal employee. }\end{array}$ \\
\hline Type of contamination event & & $\begin{array}{l}\text { Only personal clothing of worker contaminated. } \\
\text { Skin contamination involved. } \\
\text { Potential intemal contamination from inhalation/ingestion, further assessment being performed. } \\
\text { Facial/nasal contamination, possible internal contamination. } \\
\text { Internal contamination confirmed by bioassay. } \\
\text { Radionuclide(s) involved if known. State general category (i.e., beta and/or gamma, alpha, etc.) if } \\
\text { unknown. }\end{array}$ \\
\hline Extent of contamination & & $\begin{array}{l}\text { Appropriate description of clothing (e.g., pants, shoes, shirt, etc.). } \\
\text { Confined to limited area of body (e.g., tip of right index finger, hot particle on left shoulder, palm of } \\
\text { right hand, etc.). } \\
\text { If not confined, state area of body involved. } \\
\text { Maximum detected activity: }=\mathrm{dpm} / 100 \mathrm{~cm}^{2} \text {. }\end{array}$ \\
\hline $\begin{array}{l}\text { Location (area) where contamination } \\
\text { occurred \& worker activity }\end{array}$ & $\begin{array}{l}\text { a. } \\
\text { b. } \\
\text { c. }\end{array}$ & $\begin{array}{l}\text { Occurred inside of radiological area (e.g., Contamination Area, High Contamination Area, Airome } \\
\text { Radioactivity Area). } \\
\text { Occurred outside of radiological area, but onsite or within the facility. } \\
\text { State worker activity being performed at time of occurrence. }\end{array}$ \\
\hline $\begin{array}{l}\text { Significance of occurrence relative to } \\
\text { operations }\end{array}$ & $\begin{array}{l}\text { a. } \\
\text { b. } \\
\text { c. } \\
\text { d. }\end{array}$ & $\begin{array}{l}\text { Isolated event confined to room/facility/ building/area. } \\
\text { Event resulting from equipment or protective clothing malfunction. } \\
\text { Event resulting from procedural violation or deficiency. } \\
\text { Recurrent event. }\end{array}$ \\
\hline
\end{tabular}

\begin{tabular}{|c|c|c|}
\hline \multicolumn{3}{|c|}{ Immediate Action in Response to Contamination Occurrence - Item 19} \\
\hline Type of information & & Suggested statements \\
\hline 1. Status of decontamination & $\begin{array}{l}\text { b. } \\
\text { c. } \\
\text { d. }\end{array}$ & $\begin{array}{l}\text { Personal clothing retained. } \\
\text { Individual(s) successfully decontaminated below detectable levels. } \\
\text { Individual(s) decontaminated below reporting criteria; however, residual contamination persists. } \\
\text { Medical assistance required. }\end{array}$ \\
\hline
\end{tabular}

\begin{tabular}{||c||l|l|}
\hline 10.3.1.c & Type of information \\
\hline $1 . \quad$ Relative health consequence & a. $\quad \begin{array}{l}\text { Less than/Approaching } \\
\text { and/or committed effective dose limit (for any internal intake), as applicable. (Do not provide } \\
\text { comparison to site or facility administrative control level). No health consequence to individual(s). } \\
\text { Greater than applicable DOE limit, potential health consequence being evaluated. Evaluation to be } \\
\text { initiated pursuant to DOE O 225.1 requirements. } \\
\text { Concurrent injury requiring medical assistance onsite/offsite. State option a or b, as applicable, and } \\
\text { nature of injury. } \\
\text { No concurrent injury. State option a or b, as applicable. Indicate whether decontamination required } \\
\text { onsite/offsite medical assistance. }\end{array}$ \\
\hline
\end{tabular}




\subsubsection{Area or Facility Contamination Occurrences}

\begin{tabular}{|c|c|}
\hline 10.3.2.a & Description of Contamination Occurrence - Item 16 \\
\hline Type of information & Suggested statements \\
\hline 1. Location of occurrence & $\begin{array}{ll}\text { a. } & \text { Room. } \\
\text { b. Building. } \\
\text { c. Facility. } \\
\text { d. Area. } \\
\text { e. } & \text { Site. } \\
\end{array}$ \\
\hline 2. Type of contamination & $\begin{array}{l}\text { a. Spill or loss of containment } \\
\text { b. Airborne release. } \\
\text { c. Fixed/loose surface contamination. } \\
\text { d. Radionuclide(s) involved if known. State general category (i.e., beta and/or gamma, alpha, etc.) if } \\
\text { unknown. }\end{array}$ \\
\hline 3. Extent of contamination & $\begin{array}{l}\text { a. Total area involved is } \frac{\mathrm{ft}^{2} \text {. }}{\text { b. Confined within room/building/facility/area/ }} \\
\text { site. } \\
\text { c. Release beyond or containment within above locations, as applicable. }\end{array}$ \\
\hline 4. Impact on operations & $\begin{array}{l}\text { a. Normal operation not impacted. } \\
\text { b. Designated equipment removed from service. } \\
\text { c. Personnel access restricted until cleanup is completed. }\end{array}$ \\
\hline
\end{tabular}

\begin{tabular}{||c||l|l|}
\hline 10.3.2.b & Immediate Action in Response to Contamination Occurrence - Item 19 \\
\hline \hline Type of information & Suggested statements \\
\hline \hline 1. & Status of control \& decontamination & $\begin{array}{l}\text { a. } \\
\text { b. }\end{array}$ \\
\hline
\end{tabular}

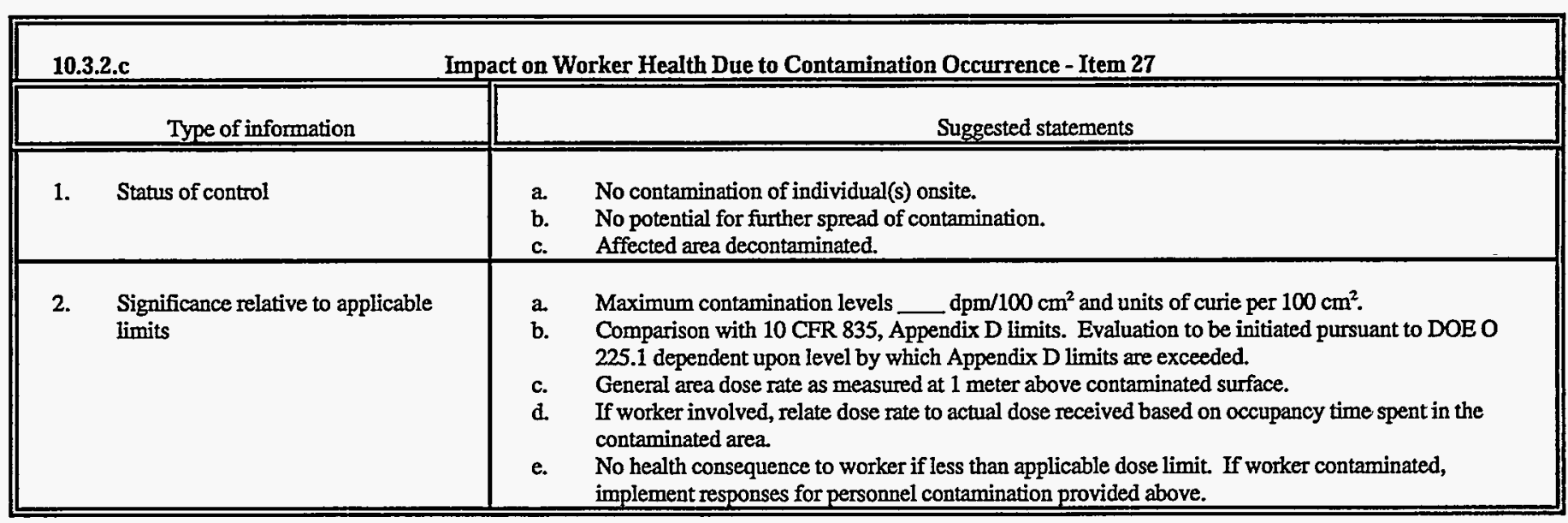




\section{REFERENCES}

10 CFR Part 71, Packaging and Transportation of Radioactive Material

10 CFR 205, 350 through 354, Report of Major Electric Utility Systems Emergencies.

10 CFR 830.350, Occurrence Reporting and Processing of Operations Information

10 CFR Part 835, Occupational Radiation Protection

$14 \mathrm{CFR}$, Aeronautics and Space

29 CFR Part 1904, Recording and Reporting Occupational Injuries and Illnesses

29 CFR Part 1910, Occupational Safety and Health Standards

36 CFR Chapter 12, Subchapter B, Records Management

40 CFR Part 261-262, Solid Wastes

40 CFR Part 355, Emergency Planning and Notification

40 CFR Part 302, Designation, Reportable Quantities, and Notification

46 CFR, Shipping

49 CFR, Parts 106-180, 200-250, and 350-399, Transportation

DOE M 471.2-1, Manual for Classified Matter Protection and Control

DOE N 441.1, Radiological Protection for DOE Activities

DOE O 151.1, Comprehensive Emergency Management System

DOE $O$ 225.1, Accident Investigations

DOE O 232.1A, Occurrence Reporting and Processing of Operations Information

DOE 0 360.1, Training

DOE O 420.1, Facility Safety

DOE O 440.1, Worker Protection Management for DOE Federal and Contractor Employees

DOE 5400.5, Radiation Protection of the Public and the Environment

DOE 5480.19, Conduct of Operations Requirements for DOE Facilities

DOE 5480.23, Nuclear Safety Analysis Reports

DOE 5480.30, Nuclear Reactor Safety Design Criteria

DOE 5632.7A, Protective Force Program

DOE/EH-0256T, Radiological Control Manual

DOE-NE-STD-1004-92, Root Cause Analysis Guidance Document

DOE-STD-1045-93, Guide to Good Practices for Notifications and Investigation of Abnormal Events

OMB No. 1200-0029, Record Keeping Guidelines for Occupational Injuries and Illnesses

12. APPENDICES. See Appendix A for definitions. 


\section{APPENDIX A}

\section{DEFINITIONS}

SCOPE: The following is a list of definitions designed to avoid repetition in the body of the document.

1. BUSINESS DAY. The normal administrative day (e.g., Monday through Friday, 0800 to 1700 ) in which normal work activities are conducted. It is not meant to encompass the 24 hours in a day, even if the facility is operated or maintained on a 24 hour basis.

2. CONDITION. Any as-found state, whether or not resulting from an event, that may have adverse safety, health, quality assurance, security, operational or environmental implications. A condition is usually programmatic in nature; for example, an error in analysis or calculation; an anomaly associated with design or performance; or an item indicating a weakness in the management process are all conditions.

3. DEFECTIVE ITEM, MATERIAL. OR SERVICE. Any item, material, or service that does not meet the commercial standard or procurement requirements as defined in catalogues, proposals, procurement specifications, design specifications, testing requirements, contracts, or the like. It includes those items or services found, during acceptance testing, preoperational testing, operations, inspections, or audit, not to meet the quality or reliability requirements appropriate to the use or specificity of the item or service procured. It also includes misrepresentation of the specifications or trademarks associated with the parts/service marking, packaging, or certification/identification stamps. It does not include parts or services which fail or are otherwise found to be inadequate because of random failures or errors within the accepted reliability level.

4. DISCHARGE. Includes, but is not limited to, any spilling, leaking, pumping, pouring, emitting, emptying, or dumping of oil, but excludes discharges in compliance with a permit under section 402 of the Clean Water Act (CWA), discharges resulting from circumstances identified and reviewed and made a part of the public record with respect to a permit issued or modified under section 402 of the CWA, and subject to a condition in such permit, or continuous or anticipated intermittent discharges from a point source, identified in a permit or permit application under section 402 of the CWA, that are caused by events occurring within the scope of relevant operating or treatment systems.

5. EVENT. Something significant and real-time that happens (e.g., pipe break, valve failure, loss of power, environmental spill, earthquake, tornado, flood). 
6. FACILITY. Any equipment, structure, system, process, or activity that fulfills a specific purpose. Examples include accelerators, storage areas, fusion research devices, nuclear reactors, production or processing plants, coal conversion plants, magnetohydrodynamics experiments, windmills, radioactive waste disposal systems and burial grounds, environmental restoration activities, testing laboratories, research laboratories, transportation activities, and accommodations for analytical examinations of irradiated and unirradiated components.

7. FACILITY MANAGER. That individual, or designee, usually but not always a contractor, with direct line responsibility for operation of a facility or group of related facilities, including authority to direct physical changes to the facility. For purposes of this Manual, a Facility Manager could also be responsible for a program or activity.

8. FACILITY REPRESENTATIVE. For each major facility or group of lesser facilities, an individual or designee assigned responsibility by the Head of Field Element/Operations Organization for monitoring the performance of the facility and its operations. This individual should be the primary point of contact with the facility operating personnel and will be responsible to the appropriate Secretarial Officer and Head of Field Element/Operations Organization for implementing the requirements of this Manual.

9. FEDERALLY PERMITTED RELEASE. Any release that satisfies the definition of "federally permitted release" in 40 CFR 302.3.

\section{HAZARDOUS SUBSTANCE OR MATERIAL.}

a. Department of Energy Office of Safeguards and Security Hazardous Material. Any solid, liquid, or gaseous material that is chemically toxic, flammable, radioactive, or unstable upon prolonged storage, and that exists in quantities that could pose a threat to life, property, or the environment.

b. Department of Transportation Hazardous Materials (see 49 CFR 171.8 and 172.101). A substance or material, including a hazardous substance, which has been determined by the Secretary of Transportation to be capable of posing an unreasonable risk to health, safety, and property when transported in commerce and which has been so designated.

c. Comprehensive Environmental Response, Compensation and Liability Act Hazardous Substances (see 40 CFR 302).

d. Occupational Safety and Health Administration (OSHA) Hazardous Chemical (see 29 CFR 1910.1000 and 29 CFR 1910.1200). Any chemical which is a physical or a health hazard.

e. Superfund Amendments and Reauthorization Act Title 3 Extremely Hazardous Substances (see 40 CFR 355). These are not defined but appear on a list in Appendix $A$ and $B$ of 40 CFR 355. 
11. ITEM.

a. An all-inclusive term used in place of the following: appurtenance, sample, assembly, component, equipment, material, module, part, structure, subassembly, subsystem, system, unit, or support systems, documented concepts, or data.

b. When used in reference to nuclear material, a visible, single piece or container of nuclear material with a unique identification and known nuclear material mass.

12. LESSONS LEARNED. A "good work practice" or innovative approach that is identified and shared, or an adverse work practice or experience that is shared to avoid recurrence.

13. LOST WORKDAYS. The number of days (consecutive or not) after, but not including, the day of injury or illness during which the employee would have worked but could not do so; that is, could not perform all or any part of his/her normal assignment during all or any part of the workday or shift because of the occupational injury or illness.

14. MEMBER OF THE PUBLIC. Persons who are not occupationally associated with the DOE facility or operations; i.e., persons whose assigned occupational duties do not require them to enter the DOE site.

15. NONREACTOR NUCLEAR FACILITY. Those activities or operations that involve radioactive and/or fissionable materials in such form and quantity that a significant nuclear hazard potentially exists to the employees or the general public. Included are activities or operations that: (1) produce, process, or store radioactive liquid or solid waste, fissionable materials, or tritium; (2) conduct separations operations; (3) conduct irradiated materials inspection, fuel fabrication, decontamination, or recovery operations; (4) conduct fuel enrichment operations; or (5) perform environmental remediation or waste management activities involving radioactive materials. Incidental use and generation of radioactive materials in a facility operation (e.g., check and calibration sources, use of radioactive sources in research and experimental and analytical laboratory activities, electron microscopes, and X-ray machines) would not ordinarily require the facility to be included in this definition. Accelerators and reactors and their operations are not included. The application of any rule to a nonreactor nuclear facility should be applied using a graded approach.

16. NOTIFICATION REPORT. The initial documented report, to the Department, of an event or condition that meets the reporting criteria defined in the Occurrence Reporting Requirements Documents.

17. NUCLEAR FACILITY. Reactor and nonreactor nuclear facilities. 
18. OCCURRENCE. An event or a condition that adversely affects, or may adversely affect, DOE or contractor personnel, the public, property, the environment, or the DOE mission. Events or conditions meeting the criteria threshold identified in DOE M 232.1-1A are occurrences.

19. OCCURRENCE INVESTIGATION. An investigation conducted according to site specific procedures and/or when determined by DOE that a Type A or B is required by DOE procedures.

20. OCCURRENCE REPORT. A documented evaluation of an event or condition that is prepared in sufficient detail to enable the reader to assess its significance, consequences, or implications and to evaluate the actions being proposed or employed to correct the condition or to avoid recurrence.

21. OCCURRENCE REPORTING REQUIREMENTS DOCUMENTS. For purposes of this Manual, these include DOE O 232.1A, OCCURRENCE REPORTING AND PROCESSING OF OPERATIONS INFORMATION, or 10 CFR 830.350 , "Occurrence Reporting and Processing of Operations Information" (when it becomes effective), whichever is appropriate, and this Manual.

22. OFFSITE TRANSPORTATION EVENT. Involves movement of materials which are considered to be in commerce, thus requiring compliance with Department of Transportation Hazardous Materials Regulations.

23. OIL. Oil of any kind or in any form, including but not limited to petroleum, fuel oil, sludge, oil refuse, and oil mixed with wastes other than dredged spoil.

24. ONSITE TRANSPORTATION EVENT. Movement of materials not in commerce and subject to DOE onsite procedures and safety requirements.

25. PERFORMANCE DEGRADATION. Failure or degradation of a facility, process, system or component that reduces the reliability of critical components of the facility whose loss or degradation prevents the system from performing its intended function. Performance degradation does not include: (1) A burned out power indicator light on a piece of radiation monitoring equipment which does not prevent the equipment from detecting elevated radiation levels and alarming as designed; (2) A piece of equipment that is determined to be out of calibration on the conservative side (such as a low level alarm that alarms at a higher value than it should); or (3) the temporary loss of a component where redundant components are maintained operable or in operation and the authorization basis is not compromised. 
26. PRIMARY ENVIRONMENTAL MONITORS. Monitoring equipment required to legally monitor ongoing discharges. In general, this term applies to monitors used closest to the point of discharge to determine if discharges are within specified limits. It also includes any equipment that actuates automatically in response to set level signals from such a monitor. It does not include equipment in general area, remediation, or compliance monitoring programs.

27. PRIMARY CONFINEMENT. Provides confinement of hazardous material to the vicinity of its processing. This confinement is typically provided by piping, tanks, glove boxes, encapsulating material, and the like, along with any offgas systems that control effluent from within the primary confinement.

28. PROGRAM MANAGER. The Headquarters individual or designee, designated by and under the direction of a Secretarial Officer, who is directly involved in the operation of facilities under his or her cognizance, and holds signature authority to provide technical direction through Heads of Field Elements/Operations Offices to operating personnel for these facilities.

29. PROGRAM SIGNIFICANT COST. Meets the criteria of Group 7.A., Cost Based Occurrences.

30. PROGRAM SIGNIFICANT DELAY. Meets the criteria of Group 8, Facility Status.

31. REACTOR. Unless it is modified by words such as containment, vessel, or core, means the entire reactor facility, including the building/structure, equipment, and associated areas devoted to the operation and maintenance of one or more reactor cores. Any apparatus that is designed or used to sustain nuclear chain reactions in a controlled manner, including critical and pulsed assemblies and research, test, and power reactors, is defined as a reactor. All assemblies designed to perform subcritical experiments which could potentially reach criticality are also to be considered reactors. Critical assemblies are special nuclear devices designed and used to sustain nuclear reactions. Critical assemblies may be subject to frequent core and lattice configuration change and may be used frequently as mockups of reactor configurations. Therefore, requirements for modification do not apply unless the overall assembly room is modified, a new assembly room is proposed, or a new configuration is not covered in previous safety evaluations (i.e., Safety Analysis Reports, Safety Analysis Report Addenda, or Technical Safety Requirements).

32. RELEASE. Any spilling, leaking, pumping, pouring, emitting, emptying, discharging, injecting, escaping, leaching, dumping, or otherwise disposing of substances into the environment. This includes abandoning/discarding any type of receptacle containing substances in an unenclosed containment structure but does not include permitted containment structures. 
33. REPORTABLE OCCURRENCE. Events or conditions to be reported in accordance with the criteria defined in the Occurrence Reporting Requirements Documents.

34. REPORTABLE QUANTITY. For any Comprehensive Environmental Response, Compensation and Liability Act hazardous substance, including radionuclides and Superfund Amendments and Reauthorization Act Title 3 extremely hazardous substances, with quantities established in 40 CFR Part 302 and Part 355 respectively, release of which requires notification unless Federally permitted.

\section{SAFETY CLASS STRUCTURES, SYSTEMS, OR COMPONENTS (SAFETY} CLASS SSCS).

Nuclear facility structures, systems, or components including primary environmental monitors and portions of process systems, whose failure could adversely affect the environment or safety and health of the public as identified by safety analyses. [DOE 5480.30]

36. SAFETY SIGNIFICANT STRUCTURES, SYSTEMS, OR COMPONENTS (SAFETY SIGNIFICANT SSCs).

a. Nuclear facility structures, systems, or components not designated as Safety Class SSCs but whose preventative or mitigative function is a major contributor to defense in depth (i.e., prevention of uncontrolled hazardous material release) and/or worker safety as determined from hazard analysis. [DOE-STD-3009-94]

b. Non-nuclear facility structures, systems, or components whose preventative or mitigative function is a major contributor to defense in depth (i.e., prevention of uncontrolled hazardous material release) and/or worker safety.

NOTE: Safety Significant SSC, as used in this Manual, distinguishes a specific category of SSCs other than Safety Class SSCs. It should not be confused with the generic modifier "safety significant" used in DOE Orders (e.g., DOE 5480.23).

37. SECRETARIAL OFFICER. Secretarial Officers are: the Secretary, Deputy Secretary, and Under Secretary; and the Assistant Secretaries and Staff Office Directors reporting to the Secretary either directly or through the Deputy Secretary or Under Secretary. The following designations are also used to identify Secretarial Officers with specific responsibilities in various areas: 1) a Program Secretarial Officer is a Head of a Departmental Element who has responsibility for a specific program or facility(ies). These include the Assistant Secretaries for Defense Programs, Energy Efficiency and Renewable Energy, Environmental Management, and Fossil Energy; and the Directors of the Offices of Civilian Radioactive Waste Management, Energy Research, and Nuclear Energy, Science and Technology; and 2) a Cognizant Secretarial Officer is a DOE official at the Assistant Secretary level who is responsible for the assignment of work, the institutional overview of any type of facility, or both, and the management oversight of a laboratory. 
38. SERVICE. The performance of work, such as design, construction, fabrication, inspection, nondestructive examination/testing, environmental qualification, equipment qualification, repair, installation, or the like.

39. SUBSTANTIAL SAFETY HAZARD. A loss of safety function to the extent that there is a major reduction in the degree of protection provided to public or worker health and safety.

40. SUPPLIER. An organization furnishing items or services. An all-inclusive term used in place of any of the following: vendor, seller, contractor, subcontractor, fabricator, distributor, consultant, or subtier suppliers.

41. TRANSPORTATION EVENT. Any real-time occurrence involving any of the following transportation activities: material classification, packaging, marking, labeling, placarding, shipping paper preparation, loading/unloading, separation/segregation, blocking and bracing, routing, accident reporting, and movement of materials. Transportation events with injury(s) may also require reporting in accordance with Group 3 criteria. 


\section{APPENDIX B}

\section{TABLE 1* \\ SURFACE ACTIVITY GUIDELINES \\ Allowable Total Residual Surface Activity (dpm/100 sq-cm) ${ }^{1}$.}

\begin{tabular}{|l|l|l|l||}
\hline Radionuclides $^{2}$ & \multicolumn{1}{|c||}{ Average $^{3 / 4}$} & Maximum $^{4 / 5}$ & Removable $^{6}$ \\
\hline $\begin{array}{l}\text { Group 1 - Transuranics, I-125, I-129, Ac-227, } \\
\text { Ra-226, Ra-228, Th-228, Th-230, Pa-231 }\end{array}$ & 100 & 300 & 20 \\
\hline $\begin{array}{l}\text { Group 2 - Th-natural, Sr-90, I-126, I-131, I-133, Ra-223, } \\
\text { Ra-224, U-232, Th-232 }\end{array}$ & 1000 & 3000 & 200 \\
\hline $\begin{array}{l}\text { Group 3 - U-natural, U-235, U-238, and associated decay } \\
\text { products, alpha emitters }\end{array}$ & 5000 & 15000 & 1000 \\
\hline $\begin{array}{l}\text { Group 4 - Beta-gamma emitters (radionuclides with decay } \\
\text { modes other than alpha emission or spontaneous fission) except } \\
\text { Sr-90 and others noted above }\end{array}$ & 5000 & 15000 & 1000 \\
\hline \hline Tritium (applicable to surface and subsurface) & & & \\
\hline
\end{tabular}

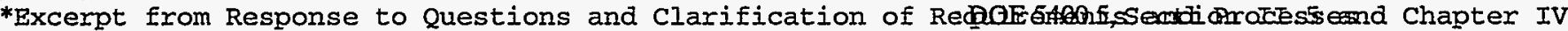

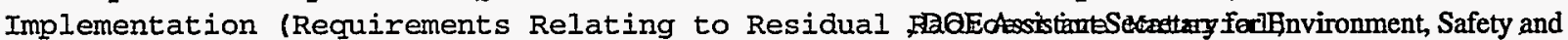
Health, Office of Environmental Policy and Assistance (EH-41), Nov. 17, 1995.

\section{NOTES:}

1 As used in this table, dpm (disintegrations per minute) means the rate of emission by radioactive material as determined by counts per minute measured by an appropriate detector for background, efficiency, and geometric factors associated with the instrumentation.

2 Where surface contamination by both alpha- and beta-gamma-emitting radionuclides exists, the limits established for alpha- and betagamma-emitting radionuclides should apply independently.

3 Measurements of average contamination should not be averaged over an area of more than $1 \mathrm{sq}-\mathrm{m}$.. For objects of smaller surface area, the average should be derived for each such object.

4 The average and maximum dose rates associated with surface contamination resulting from beta-gamma emitters should not exceed $0.2 \mathrm{mrad} / \mathrm{h}$ and $1.0 \mathrm{mrad} / \mathrm{h}$, respectively, at $1 \mathrm{~cm}$.

5 The maximum contamination level applies to an area of not more than $100 \mathrm{sq}-\mathrm{cm}$.

6 The amount of removable material per $100 \mathrm{sq}-\mathrm{cm}$ of surface area should be determined by wiping an area of that size with dry filter or soft absorbent paper, applying moderate pressure, and measuring the amount of radioactive material on the wiping with an appropriate instrument of known efficiency. When removable contamination on objects of surface area less than $100 \mathrm{sq}-\mathrm{cm}$ is determined, the activity per unit area should be based on the actual area and the entire surface should be wiped. It is not necessary to use wiping techniques to measure removable contamination levels if direct scan surveys indicate that the total-residual surface contamination levels are within the limits for removable contamination.

7 This category of radionuclides includes mixed fission products, including the Sr-90 which is present in them. It does not apply to Sr90 which has been separated from the other fission products or mixtures where the $\mathrm{Sr}-90$ has been enriched.

8 Property recently exposed or decontaminated should have measurements (smears) at regular time intervals to ensure that there is not a build-up of contamination over time. Because tritium typically penetrates material it contacts, the surface guidelines in Group 4 are not applicable to tritium. The Department has reviewed the analysis conducted by the DOE Tritium Surface Contamination Limits Committee (Recommended Tritium Surface Contamination Release Guides, February 1991), and has assessed potential doses associated with the release of property containing residual tritium. The Department recommends the use of the stated guideline as an interim value for removable tritium. Measurements demonstrating compliance of the removable fraction of tritium on surfaces with this guideline are acceptable to ensure that non-removable fractions and residual tritium in mass will not cause exposures that exceed DOE dose limits and constraints. 